\title{
Distribution of gaseous and particulate organic composition during dark $\alpha$-pinene ozonolysis
}

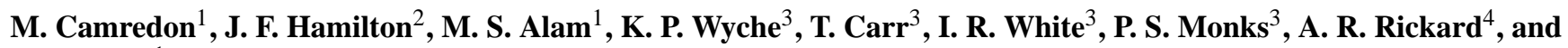 \\ W. J. Bloss ${ }^{1}$ \\ ${ }^{1}$ School of Geography, Earth \& Environmental Sciences, University of Birmingham, Birmingham, B15 2TT, UK \\ ${ }^{2}$ Department of Chemistry, University of York, York, YO10 5DD, UK \\ ${ }^{3}$ Department of Chemistry, University of Leicester, Leicester, LE1 7RH, UK \\ ${ }^{4}$ National Centre for Atmospheric Science, School of Chemistry, University of Leeds, Leeds, LS2 9JT, UK
}

Received: 4 December 2009 - Published in Atmos. Chem. Phys. Discuss.: 23 December 2009

Revised: 11 March 2010 - Accepted: 15 March 2010 - Published: 29 March 2010

\begin{abstract}
Secondary Organic Aerosol (SOA) affects atmospheric composition, air quality and radiative transfer, however major difficulties are encountered in the development of reliable models for SOA formation. Constraints on processes involved in SOA formation can be obtained by interpreting the speciation and evolution of organics in the gaseous and condensed phase simultaneously. In this study we investigate SOA formation from dark $\alpha$-pinene ozonolysis with particular emphasis upon the mass distribution of gaseous and particulate organic species. A detailed model for SOA formation is compared with the results from experiments performed in the EUropean PHOtoREactor (EUPHORE) simulation chamber, including on-line gas-phase composition obtained from Chemical-Ionization-Reaction Time-Of-Flight Mass-Spectrometry measurements, and off-line analysis of SOA samples performed by Ion Trap Mass Spectrometry and Liquid Chromatography. The temporal profile of SOA mass concentration is relatively well reproduced by the model. Sensitivity analysis highlights the importance of the choice of vapour pressure estimation method, and the potential influence of condensed phase chemistry. Comparisons of the simulated gaseous- and condensed-phase mass distributions with those observed show a generally good agreement. The simulated speciation has been used to (i) propose a chemical structure for the principal gaseous semi-volatile organic compounds and condensed monomer organic species, (ii) provide evidence for the occurrence of recently suggested radical
\end{abstract}

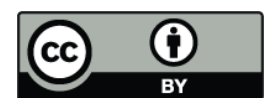

Correspondence to: M. Camredon (m.camredon@bham.ac.uk) isomerisation channels not included in the basic model, and (iii) explore the possible contribution of a range of accretion reactions occurring in the condensed phase. We find that oligomer formation through esterification reactions gives the best agreement between the observed and simulated mass spectra.

\section{Introduction}

Secondary Organic Aerosol (SOA) has received significant interest because of its potential impact on climate, air quality and human health (e.g. Kanakidou et al., 2005). Quantification of the impacts of SOA requires simulating SOA production and chemical speciation, and thus implementing processes leading to SOA formation in 3-D chemical transport models (e.g. Fuzzi et al., 2006). SOA is formed by nucleation and/or condensation onto pre-existing particles of low volatility degradation products produced during the oxidation of Volatile Organic Compounds (VOC) (e.g. Kanakidou et al., 2005; Seinfeld and Pankow, 2003; Kroll and Seinfeld, 2008; Hallquist et al., 2009). However, the sheer number of individual compounds involved in gas-phase oxidation leads to major difficulties in representing SOA formation on a theoretical basis (e.g. Goldstein and Galbally, 2007). SOA formation is commonly empirically parameterized on the basis of mass yields observed in smog chamber experiments (e.g. Odum et al., 1996). Comparisons of simulated SOA mass with in situ observations highlight a systematic underestimation of SOA production, increasing broadly with air mass ageing (e.g. Volkamer et al., 2006). The current

Published by Copernicus Publications on behalf of the European Geosciences Union. 
parameterizations used in 3-D models require improvements to represent (i) SOA formation under a wide range of atmospheric chemical and physical conditions and (ii) SOA chemical speciation and its evolution during air mass ageing.

Simulation of SOA formation and composition requires theoretical models that describe in detail (i) the formation of Semi-Volatile Organic Compounds (SVOC) from gaseous oxidation (initiated by reactions with $\mathrm{OH}, \mathrm{O}_{3}, \mathrm{NO}_{3}$ or photolysis) of the VOC precursors, (ii) the partitioning of each individual SVOC between the gaseous and the condensed phases, and (iii) the potential reactivity of the condensed SVOC within the particulate phase. While such detailed mechanisms may be too large in size to be implemented in 3-D chemical transport models, their evaluation against laboratory chamber experiments is essential to evaluate and improve our understanding of processes involved in SOA formation.

A number of studies have reported comparisons between chamber experiments and detailed models for SOA production from a range of biogenic and aromatic organic compounds which are known to be major SOA precursors (e.g. Jenkin, 2004; Stroud et al., 2004; Johnson et al., 2004, 2005; Capouet et al., 2008; Xia et al., 2008). Results from these studies have shown that model predictions can differ significantly from observations (Jenkin, 2004; Stroud et al., 2004; Johnson et al., 2004, 2005; Xia et al., 2008). For example Jenkin (2004) had to apply a scaling factor of two orders of magnitude to all rate constants for gas/particle partitioning in a model to simulate the final SOA mass observed during an $\alpha$-pinene chamber oxidation experiment. Model performances have also been found to vary with the experimental conditions (i.e. temperature, relative humidity, $\mathrm{NO}_{\mathrm{x}}$ levels, initial concentration of precursors) (Stroud et al., 2004; Johnson et al., 2004, 2005; Xia et al., 2008). For example, Xia et al. (2008) have shown that their model simulations of $22 \alpha-$ pinene oxidation experiments reproduced the observed SOA mass to within a factor varying from $1.87 \times 10^{-4}$ to 1.57 , depending upon experimental conditions. Finally, these studies have shown that results can significantly differ from one detailed SOA model to another. For the example of SOA formation from $\alpha$-pinene oxidation, some models have difficulties in reproducing observed SOA mass to within an order of magnitude (Jenkin, 2004; Xia et al., 2008), whereas Capouet et al. (2008) have shown that their model simulated the SOA mass observed during $28 \alpha$-pinene photooxidation experiments performed under a wide range of photochemical conditions in most cases to within a factor of 2. Many of these problems with simulated SOA mass are a consequence of uncertainties in our understanding of the detailed processes involved in SOA formation.

At present, three major difficulties are encountered in the development of reliable models for SOA formation:

1. the gaseous chemical pathways leading to the formation of SVOC are far from fully identified. Gaseous oxidation produces a multitude of individual SVOC, possibly formed after several oxidation steps of the precursor (e.g. Aumont et al., 2005). The majority of SVOC remain uncharacterised in the gaseous as well as in the condensed phases (e.g. Hallquist et al., 2009). Furthermore, large uncertainties still exist over the degradation mechanisms of multi-functionalised organics (e.g. Kroll and Seinfeld, 2008). Therefore assumptions and simplifications are implemented in the chemical schemes which represent the formation of gaseous SVOC.

2. the reactivity of SVOC in the condensed phase is poorly understood. High molecular weight organics have been detected in the condensed phase (e.g. Jang et al., 2002; Gao et al., 2004; Kalberer et al., 2004; Tolocka et al., 2004; Hamilton et al., 2006). This evidence strongly suggests the presence of accretion reactions occurring in the condensed phase, such as peroxyhemiacetal formation, hemiacetal formation, aldol condensation or esterification, and/or in the gaseous phase, such as peroxy radical self reactions or Stabilized Criegee Intermediate (SCI) reactions with other oxygenates (e.g. Kroll and Seinfeld, 2008). Such reactions could enhance the uptake of organic material to the condensed phase and its subsequent retention (e.g. Jang et al., 2002; Czoschke et al., 2003; Jenkin, 2004; Johnson et al., 2004, 2005). To date few such oligomer species have been characterised, and chemical schemes representing the reactivity of SVOC in the condensed phase are largely conceptual (e.g. Jenkin, 2004; Johnson et al., 2004, 2005; Capouet et al., 2008).

3. the thermodynamic properties controlling the gas/particle partitioning of each SVOC are uncertain. The gas/particle partitioning of SVOC is expected to occur via an absorption process (e.g. Pankow, 1994a; Pankow, 1994b). The absorption of each SVOC is then controlled by its saturation vapour pressure. Considering the large number of SVOC contributing to SOA formation, estimation methods are required to calculate this property in detailed models. However, the uncertainty in vapour pressure estimates for SVOC can reach several orders of magnitudes (e.g. Asher et al., 2002; Asher and Pankow, 2006; Camredon and Aumont, 2006; Clegg et al., 2008; Barley and McFiggans, 2010). These large uncertainties are then directly propagated through the gas/particle partitioning reactions, and hence to the calculated SOA mass.

Constraints on processes involved in SOA formation can be obtained from comparisons of detailed model simulations with laboratory experiments that track the distribution and the evolution of SVOC in both the gaseous and condensed phases. 
Table 1. Analytical instrumentation coupled to the EUPHORE chamber during the $\alpha$-pinene ozonolysis experiments.

\begin{tabular}{lll}
\hline Target species & Instrument & Detection limit \\
\hline Environmental parameters & & few ppm \\
$\mathrm{H}_{2} \mathrm{O}$ & Dew-Point Hygrometer & \\
Inorganic species & & $1 \mathrm{ppb}$ \\
$\mathrm{O}_{3}$ & UV photometric ozone analyser & $5 \mathrm{ppb}$ \\
$\mathrm{CO}$ & IR absorption CO analyser (TE48C) & $\sim 0.2 \mathrm{ppb}$ for NO \\
$\mathrm{NO} / \mathrm{NO}_{2}$ & Photolytic chemiluminescence $\mathrm{NO}_{\mathrm{x}}$ analyzer & \\
$\mathrm{Radicals}$ & & $1 \times 10^{6} \mathrm{molec}^{-3} / 0.1 \mathrm{ppt}$ \\
$\mathrm{OH} / \mathrm{HO}_{2}$ & LIF & \\
$\mathrm{Gaseous}$ organic species & & $1 \mathrm{ppb}$ \\
$\mathrm{HCHO}$ & $\mathrm{HCHO}$ Monitor (AL41) & $\sim 1 \mathrm{ppb}$ \\
Oxygenated carbonyls, hydroperoxides & HPLC & sub-ppb \\
VOC, oxygenated VOCs & CIR-TOF-MS & \\
Aerosol organic species & & \\
Aerosol volume and size & SMPS (TSI 3081/3022) & \\
SOA (filter sampling) & ESI-MS & \\
& LC-MS & \\
\hline
\end{tabular}

The aim of the present paper is to explore SOA formation from the dark ozonolysis of $\alpha$-pinene, with particular emphasis upon the distribution of gaseous and particulate SVOC. The reaction of $\alpha$-pinene with ozone is a major source of atmospheric SOA (e.g. Kanakidou et al., 2005) and hence has been the subject of numerous studies. $\alpha$-pinene ozonolysis provides a good test case as a relatively complete identification of gaseous and particulate products exists. The methodology is based on a comparison of observations carried out in a large atmospheric simulation chamber against simulations performed with a detailed model of gaseous and condensed phase composition. The experimental work was performed in the EUropean PHOtoREactor facility (EUPHORE), with analytical instrumentation selected to ensure comprehensive detection of organic species distributed within the gaseous and condensed phases. Key techniques for providing the entire mass spectrum of species were Chemical-Ionization-Reaction Time-Of-Flight MassSpectrometry (CIR-TOF-MS) (e.g. Blake et al., 2004) for on-line analysis of a wide range of gaseous organics and Liquid Chromatography and ElectroSpray Ionisation ion trap Mass Spectrometry (ESI-MS and LC-MS ${ }^{\mathrm{n}}$ ) (e.g. Hamilton et al., 2008) for off-line analysis of SOA filter samples. The EUPHORE facility, instrumentation used and experimental conditions are described in Sect. 2. A detailed chamber specific box model incorporating the complete gas-phase $\alpha$ pinene oxidation scheme, extracted from the Master Chemical Mechanism version 3.1 (MCMv3.1) (Jenkin et al. 1997, 2003; Saunders et al., 2003; Bloss et al., 2005a), was coupled to a gas/particle partitioning module for comparison with observations. The SOA formation model is presented in Sect. 3. The results of simulations of SOA mass from $\alpha$-pinene dark ozonolysis are presented in Sect. 4. The simulated and observed gaseous and particulate distributions of organics are compared in Sect. 5.

\section{Experimental setup}

\subsection{The EUPHORE facility}

The experiments were conducted at the EUropean PHOtoREactor (EUPHORE) facility in Valencia (Spain) as part of the UK NERC-funded TRAPOZ (Total RAdical Production and degradation Products from Alkene OZonolysis) project. The EUPHORE facility consists of two outdoor atmospheric simulation chambers located on the roof of the Centro de Estudios Ambientales del Mediterraneo (CEAM) building. Technical details concerning the simulation chambers are given in Becker et al. (1996). Briefly, each hemispheric photo-reactor is $\sim 200 \mathrm{~m}^{3}$ in volume and is constructed from Fluorine-Ethene-Propene film (FEP). The reactors are surrounded by retractable steel covers allowing both dark and photolysis experiments to be carried out. Fans located inside the chambers ensure rapid homogenized mixing. Experiments are carried out at ambient temperature and close to the atmospheric pressure. Losses from sampling into the analytical instruments, and any leakage, are compensated for by periodical introductions of purified air into the chamber (both chambers are marginally over pressurised in order to prohibit ambient air ingress). The analytical instrumentation is located on a platform directly under each reactor.

\subsection{Analytical instrumentation}

The analytical instrumentation coupled to the EUPHORE chamber during the experiments are listed in Table 1. The 
Table 2. Initial concentrations of precursors and mean environmental parameters for the $\alpha$-pinene+O $\mathrm{O}_{3}$ and $\alpha$-pinene+O ${ }_{3}+\mathrm{CO}$ EUPHORE experiments.

\begin{tabular}{|c|c|c|c|c|c|c|c|}
\hline & {$[\alpha \text {-pinene }]_{0}$} & {$\left[\mathrm{O}_{3}\right]_{0}$} & $\begin{array}{l}{[\mathrm{CO}]_{0}} \\
(\mathrm{ppb})\end{array}$ & $\begin{array}{l}T \\
(\mathrm{~K})\end{array}$ & $\begin{array}{l}\mathrm{H}_{2} \mathrm{O} \\
\left(\operatorname{molec~cm}{ }^{-3}\right)\end{array}$ & $\begin{array}{l}\text { Gaseous } \\
\text { dilution } \\
\text { rate }\left(s^{-1}\right)\end{array}$ & $\begin{array}{l}\text { Aerosol } \\
\text { loss } \\
\text { rate }\left(s^{-1}\right)\end{array}$ \\
\hline$\alpha$-pinene $+\mathrm{O}_{3}$ & $\begin{array}{l}12 \mathrm{ppb} \min ^{-1} \\
\text { (over } 15 \mathrm{~min} \text { ) }\end{array}$ & $209.3 \mathrm{ppb}$ & 448 & 293 & $1.85 \times 10^{15}$ & $8.2 \times 10^{-5}$ & $1.2 \times 10^{-4}$ \\
\hline$\alpha$-pinene $+\mathrm{O}_{3}+\mathrm{CO}$ & $159.2 \mathrm{ppb}$ & $\begin{array}{l}20 \mathrm{ppb} \min ^{-1} \\
\text { (over } 6 \mathrm{~min} \text { ) }\end{array}$ & $6.73 \times 10^{5}$ & 297 & $1.93 \times 10^{15}$ & $3.8 \times 10^{-5}$ & $1.2 \times 10^{-4}$ \\
\hline
\end{tabular}

facility is equipped with a range of instruments measuring the environmental conditions inside the chamber (temperature, pressure, humidity and photolysis rates). Standard monitors were used to follow the temporal evolution of inorganic species $\left(\mathrm{O}_{3}, \mathrm{CO}, \mathrm{NO}_{\mathrm{x}}\right)$. The $\mathrm{OH}$ and $\mathrm{HO}_{2}$ radical levels were measured on-line using Laser Induced Fluorescence (LIF) (Bloss et al., 2004).

Measurements of the temporal evolution of the gas phase degradation products were made using traditional analytical techniques permanently available at EUPHORE, namely a formaldehyde monitor and various chromatographic instruments (Gas Chromatography-Mass Spectrometer - GC-MS and a High Performance Liquid Chromatography - HPLC). Details concerning the permanent EUPHORE instrumentation are also given in Becker et al. (1999). The chamber instrumentation was supplemented by a Chemical-IonizationReaction Time-Of-Flight Mass-Spectrometer (CIR-TOFMS) (Blake et al., 2004; Wyche et al., 2007, 2009), for the detection of a wide range of VOC at the ppb-sub-ppb (partsper-billion by volume) level.

The temporal evolution of aerosol physical characteristics (size, number and volume distribution) was provided by Scanning Mobility Particle Sizer (SMPS), combining a Differential Mobility Analyser (DMA) and a Condensation Particle Counter (CPC). Aerosol samples were collected onto filters at the end of each experiment and the composition was analysed off-line. Filters were extracted into high purity water (Hamilton et al., 2008), and the mass distribution profile of the sample was obtained using direct infusion of the water soluble extract (via a syringe pump) into an ElectroSpray Ionisation source coupled to an ion trap Mass Spectrometer (ESI-MS). The chemical structures of SOA components were obtained using reverse phase Liquid Chromatography, to separate individual components, and fragmentation patterns obtained using collision induced dissociation in the ion trap MS (LC-MS ${ }^{\mathrm{n}}$ ) (Hamilton et al., 2006, 2008).

\subsection{Experimental protocol}

The experiments were performed at levels of reactants approaching (i.e. relevant to) atmospheric conditions (see
Table 2). In order to exclude photochemical effects, the experiments were performed in the dark with the chamber housing closed $\left(j\left(\mathrm{NO}_{2}\right)<2 \times 10^{-5} \mathrm{~s}^{-1}\right)$. The ozonolysis experiments were carried out under $\mathrm{NO}_{\mathrm{x}}$-free conditions ([NO] and $\left[\mathrm{NO}_{2}\right]$ below the monitor detection limit of 0.2 and $0.5 \mathrm{ppb}$ respectively) and low relative humidity $\left(\left[\mathrm{H}_{2} \mathrm{O}\right] \sim 2 \times 10^{15}\right.$ molec $\left.\mathrm{cm}^{-3}\right)$. Two types of experiments were performed. A first experiment was carried out to observe SOA formation from a mixture composed of $\alpha$-pinene and ozone. A second type of experiment involved the observation of SOA formation from a mixture composed of $\alpha$ pinene, $\mathrm{O}_{3}$ and an $\mathrm{OH}$ scavenger. In our experiment, $\mathrm{CO}$ was used as the $\mathrm{OH}$ scavenger. The amount of $\mathrm{CO}$ added inside the chamber was selected in order to ensure more than $95 \%$ of the $\alpha$-pinene chemical removal was due to $\mathrm{O}_{3}$.

An aliquot of $\mathrm{SF}_{6}$ was introduced to the chamber as an inert tracer to determine the dilution rate. For the experiment with an $\mathrm{OH}$ scavenger, the carbon monoxide (manufactured purity $>99 \%$, used as supplied) was injected directly. Ozone, produced from a silent discharge in pure oxygen (Linde, purity of $99.999 \%$ ) with a typical production rate of $20 \mathrm{ppb} \mathrm{min}^{-1}$, was supplied to the simulation chamber in a flow of purified air. Subsequently a known liquid volume of $\alpha$-pinene (manufactured purity $>99 \%$, used as supplied) was evaporated by heating through a purified air stream flowing into the chamber. The aerosol sample for ESI-MS and LC$\mathrm{MS}^{\mathrm{n}}$ chemical analysis was collected on $47 \mathrm{~mm}$ quartz-fibre filters for a period of $\sim 1 \mathrm{~h}$ at a flow rate of $74 \mathrm{~L} \mathrm{~min}^{-1}$, commencing when the $\alpha$-pinene level had fallen to $\sim 20 \%$ of its initial peak. Samples were immediately frozen and kept below $-15^{\circ} \mathrm{C}$ until analysis.

\section{SOA modelling}

\subsection{Gaseous chemical scheme}

The complete detailed gas-phase oxidation scheme for $\alpha$ pinene was extracted from the Master Chemical Mechanism version 3.1 (MCMv3.1), which is directly accessible from the website: http://mcm.leeds.ac.uk/MCM. The MCM is a 


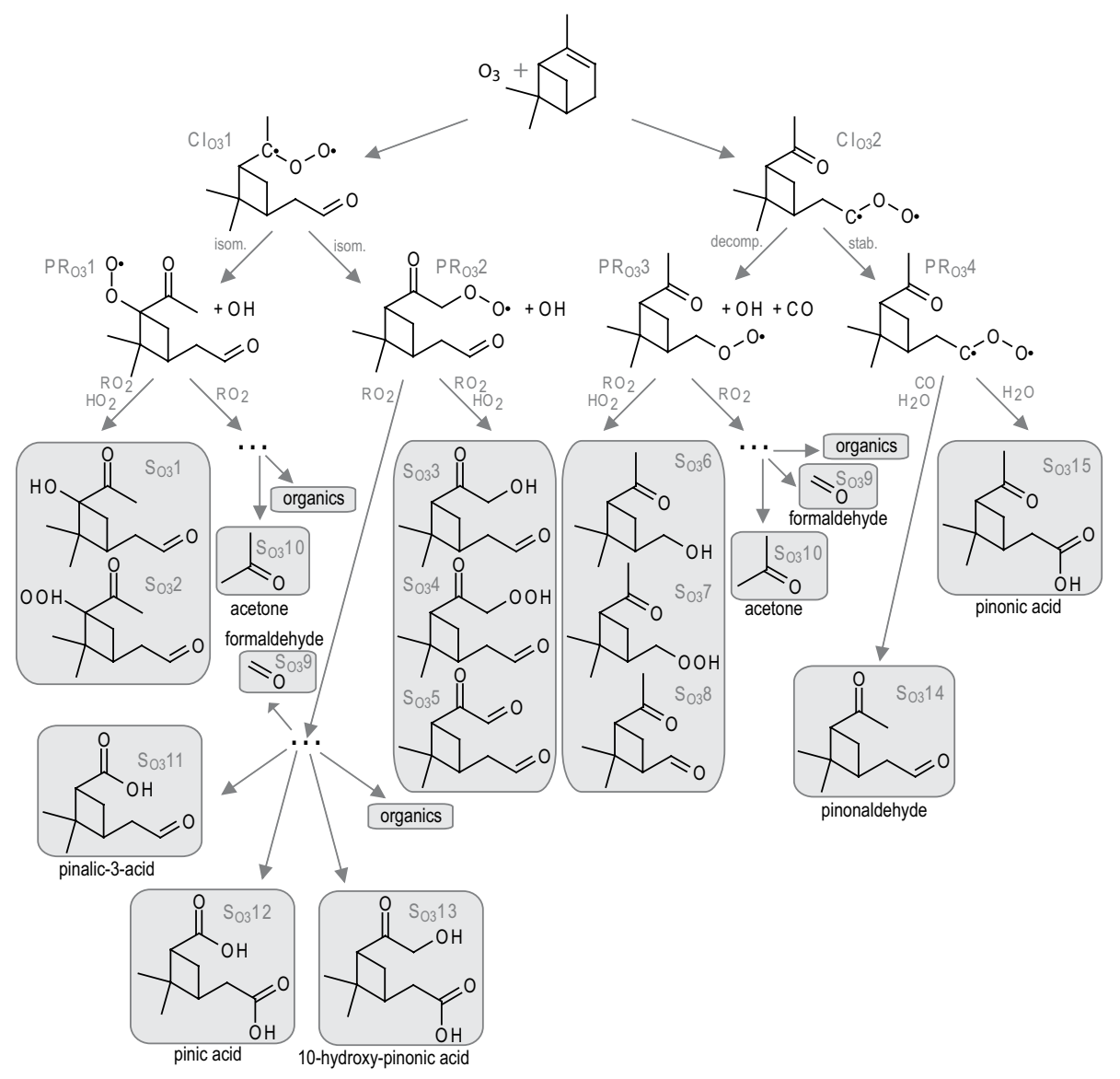

Fig. 1. First oxidation pathways in the $\mathrm{O}_{3}$-initiated $\alpha$-pinene oxidation mechanism as represented in the MCMv3.1. The framed compounds are stable first generation species. The dots indicate chemical pathways not represented explicitly on the figure.

near explicit mechanism describing the complete degradation of 135 primary emitted VOC into $\mathrm{CO}_{2}$ and $\mathrm{H}_{2} \mathrm{O}$. The subset of the MCMv3.1 describing $\alpha$-pinene oxidation contains $\sim 320$ organic species evolving according to 920 reactions (prior to being coupled to a suitable set of inorganic reactions). In photochemical simulation chamber experiments, heterogeneous wall losses and conversion reactions need to be characterised and taken into account. However, under the conditions of the experiments studied (i.e. dark and $\mathrm{NO}_{\mathrm{x}}-$ free) these wall processes are expected to be minimal. Only ozone wall losses on the EUPHORE chamber were implemented in the box model with a kinetic rate of $3 \times 10^{-6} \mathrm{~s}^{-1}$ (Bloss et al., 2005b). The protocol applied to derive the $\alpha$ pinene oxidation scheme is presented in detail in Jenkin et al. (2000) and Saunders et al. (2003). During $\mathrm{NO}_{\mathrm{x}}$-free dark ozonolysis experiments, the oxidation of $\alpha$-pinene can be initiated by both $\mathrm{O}_{3}$ and $\mathrm{OH}$. The first oxidation stages of these degradation processes as represented in the MCMv3.1 (under $\mathrm{NO}_{\mathrm{x}}$-free conditions) are briefly described below.
The first stages of $\mathrm{O}_{3}$-initiated $\alpha$-pinene oxidation are shown in Fig. 1. The initial step consists of the concerted addition of ozone to the $>\mathrm{C}=\mathrm{C}<$ double bond of $\alpha$-pinene, leading to the formation of an energy-rich primary ozonide. This ozonide is expected to undergo rapid bond cleavage and isomerisation, giving two ring opened excited Criegee Intermediates (CI) with a carbonyl substituent (denoted $\mathrm{CI}_{\mathrm{O} 3} 1$ and $\mathrm{CI}_{\mathrm{O} 3} 2$ in Fig. 1). The $\mathrm{CI}_{\mathrm{O} 3} 1$ and $\mathrm{CI}_{\mathrm{O} 3} 2$ are assumed to decompose to yield $\mathrm{OH}$ and peroxy radicals $\mathrm{PR}_{\mathrm{O} 3} 1, \mathrm{PR}_{\mathrm{O} 3} 2$ or $\mathrm{PR}_{\mathrm{O}_{3}} 3$. These peroxy radicals react with $\mathrm{HO}_{2}$ and other $\mathrm{RO}_{2}$ leading to the formation of stable species either directly $\left(\mathrm{S}_{\mathrm{O}} 1\right.$ to $\mathrm{S}_{\mathrm{O} 3} 8$ ) or after further $\mathrm{RO}_{2} / \mathrm{RO}$ conversions and intermolecular isomerisations. These chemical pathways lead to the formation of various secondary organics including the first generation oxidation products previously observed such as formaldehyde, acetone, pinalic-3-acid, pinic acid and 10hydroxy-pinonic acid ( $\mathrm{S}_{\mathrm{O} 3} 9$ to $\mathrm{S}_{\mathrm{O} 3} 11$ respectively). The $\mathrm{CI}_{\mathrm{O} 3} 2$ may also be stabilized by collisions. The thermally stabilized Criegee $\left(\mathrm{PR}_{\mathrm{O} 3} 4\right)$ may undergo bimolecular reactions with $\mathrm{H}_{2} \mathrm{O}, \mathrm{CO}$ and/or other oxygenated organics (or $\mathrm{NO}$ in the ambient atmosphere) to produce pinonaldehyde $\left(\mathrm{S}_{\mathrm{O} 3} 14\right)$ and pinonic acid $\left(\mathrm{S}_{\mathrm{O} 3} 15\right)$. Despite considerable 


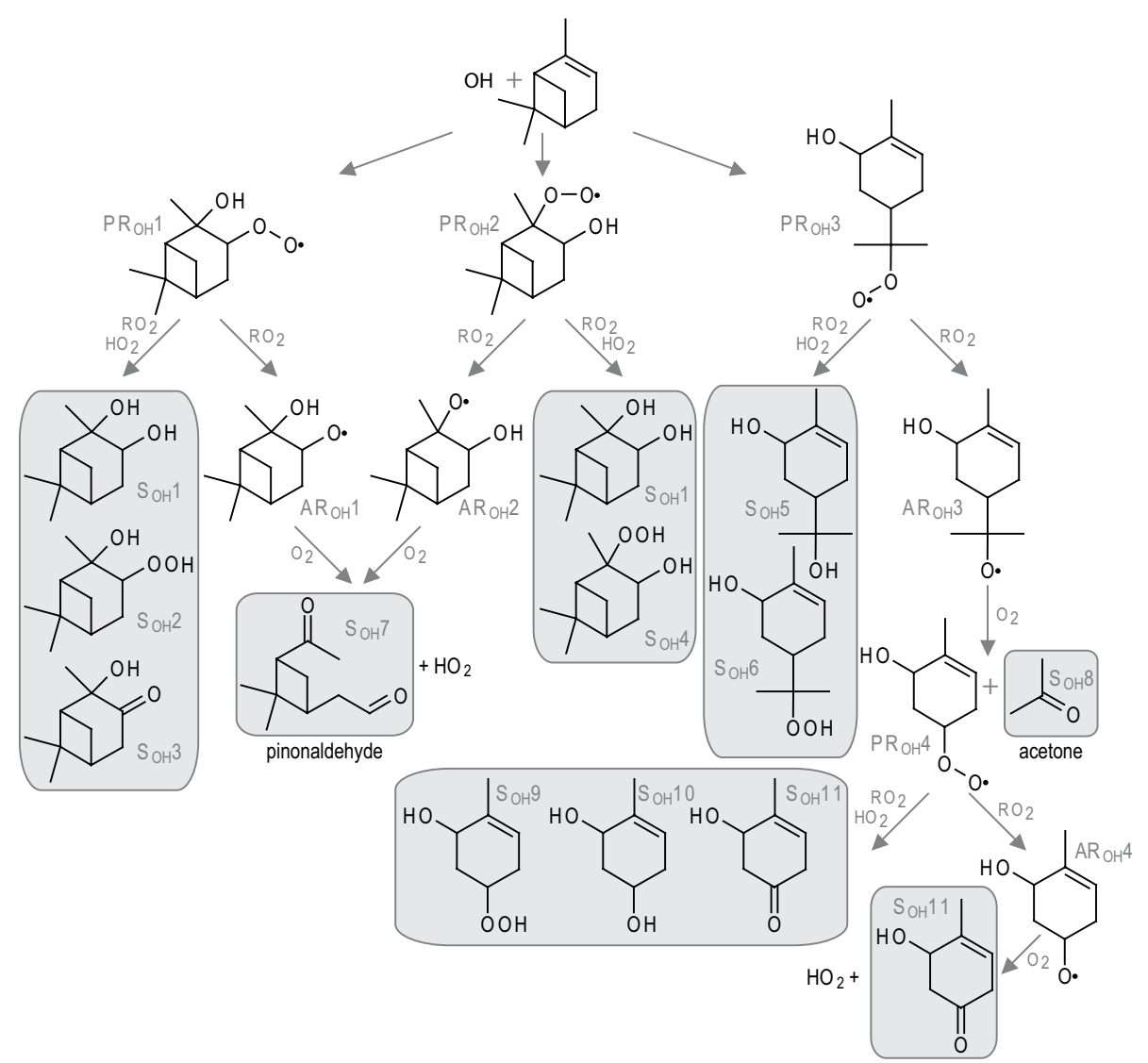

Fig. 2. First oxidation pathways in the $\mathrm{OH}$-initiated $\alpha$-pinene oxidation mechanism as represented in the MCMv3.1. The framed compounds are stable first generation species.

study, large uncertainties still exist over the possible fates of the Criegee intermediates that lead to the formation of observed secondary products during the $\mathrm{O}_{3}$-initiated $\alpha$-pinene oxidation (e.g. Johnson and Marston, 2008).

The initial oxidation pathways involved in the $\mathrm{OH}$ initiated $\alpha$-pinene oxidation are shown in Fig. 2. The initial step proceeds through the addition of $\mathrm{OH}$ to the $>\mathrm{C}=\mathrm{C}<$ double bond of $\alpha$-pinene, forming a secondary or tertiary hydroxyl-substituted alkyl radical. These alkyl radicals react rapidly with $\mathrm{O}_{2}$ to form the corresponding peroxy radicals (denoted $\mathrm{PR}_{\mathrm{OH}} 1$ and $\mathrm{PR}_{\mathrm{OH}} 2$ in Fig. 2). A fraction of the tertiary alkyl radical is also assumed to isomerise by ring opening prior to $\mathrm{O}_{2}$ addition, giving the peroxy radical $\mathrm{PR}_{\mathrm{OH}} 3$. These peroxy radicals recombine with $\mathrm{HO}_{2}$ and other $\mathrm{RO}_{2}$ to form stable species $\left(\mathrm{S}_{\mathrm{OH}} 1\right.$ to $\left.\mathrm{S}_{\mathrm{OH}} 6\right)$ or their corresponding alkoxy radicals $\left(\mathrm{AR}_{\mathrm{OH}} 1, \mathrm{AR}_{\mathrm{OH}} 2\right.$ and $\left.\mathrm{AR}_{\mathrm{OH}} 3\right)$. The alkoxy radicals $\mathrm{AR}_{\mathrm{OH}} 1$ and $\mathrm{AR}_{\mathrm{OH}} 2$ are assumed to exclusively produce pinonaldehyde (product $\mathrm{S}_{\mathrm{OH}} 7$ ) after $\mathrm{C}-\mathrm{C}$ bond scission and $\mathrm{H}$ abstraction by $\mathrm{O}_{2}$. The $\mathrm{AR}_{\mathrm{OH}} 3$ radical is considered to decompose into acetone $\left(\mathrm{S}_{\mathrm{OH}} 8\right)$ and a peroxy radical $\mathrm{PR}_{\mathrm{OH}} 4$ which then follow the usual $\mathrm{RO}_{2}$ reactions to give the $\mathrm{S}_{\mathrm{OH}} 9$ to $\mathrm{S}_{\mathrm{OH}} 11$ stable species. Theoretical studies have demonstrated the existence of a number of alternative pathways in the $\mathrm{OH}$-initiated $\alpha$-pinene oxidation involving intramolecular isomerisations (e.g. Peeters et al., 2001; Fantechi et al., 2002; Vereecken and Peeters, 2004; Vereecken et al., 2007). These processes were not considered in our model, and it is important to note that the existence of these chemical pathways could lead to a different distribution of organic species formed during the gaseous oxidation and have a substantial impact on SOA formation.

\subsection{Gas/particle partitioning of organic compounds}

The gas/particle partitioning of organic compounds was implemented as described in Camredon et al. (2007). The absorption of each SVOC produced during $\alpha$-pinene ozonolysis was represented assuming a thermodynamic equilibrium between the gas and particle phases, as described in Pankow (1994a, b). The thermodynamic equilibrium for each SVOC was calculated using Raoult's law:

$P_{i}=x_{i} \gamma_{i} P_{i}^{\mathrm{vap}}$,

where $P_{i}$ is the equilibrium partial pressure of a species $i, x_{i}$ its mole fraction in the condensed phase, $P_{i}^{\text {vap }}$ its vapour pressure as a pure liquid at the temperature of interest 
and $\gamma_{i}$ its activity coefficient in the condensed phase. The gas/particle equilibria were applied to the full set of stable (i.e. non-radical) organic species formed during $\alpha$-pinene oxidation (around 180 species as described in the MCMv3.1). As aerosol particles are expected to be composed of organic molecules with a similar structure, we make the approximation that $\gamma_{i}$ may be set to unity (e.g. Seinfeld and Pankow, 2003). The liquid vapour pressure (probably subcooled) of the organic species was estimated using the Myrdal and Yalkowsky method (Myrdal and Yalkowsky, 1997) coupled with the Joback structure/property relationship for boiling point estimates (e.g. Reid et al., 1986), considering its reliability for SVOC generated during gas-phase oxidation (Camredon and Aumont, 2006); alternative choices are discussed in detail in Sect. 4. No chemical reactions were implemented in the condensed phase.

\subsection{Box model}

The gas-phase kinetic and the gas/particle partitioning modules were implemented in a zero-dimensional box model (Martin, 2009). The two modules were solved by operator splitting and treated as consecutive operators. The gas-phase kinetic module was integrated with the CVODE solver as downloaded from the SUNDIALS (SUite of Nonlinear and DIfferential/ALgebraic equation Solvers) website (https://computation.llnl.gov/casc/sundials/main.html). The absorptive gas/particle partitioning module was solved using the iterative method described in Pankow (1994b). The partitioning processes between the gas and condensed phases were solved with an operator time step of $1 \mathrm{~min}$, as an operator time step below $5 \mathrm{~min}$ was required to prevent the introduction of errors associated with operator splitting.

The box model was initialised with the environmental conditions and initial concentrations shown in Table 2 in order to simulate the experimental conditions. The simulation was initialised at a time point corresponding to the precursor injection for the $\alpha$-pinene $+\mathrm{O}_{3}$ experiment and the ozone injection for the $\alpha$-pinene $+\mathrm{O}_{3}+\mathrm{CO}$ experiment (shown at time zero in Fig. 3). The observed injection profiles were implemented as a constant flux that reproduced the observed $\alpha$-pinene (for the $\alpha$-pinene $+\mathrm{O}_{3}$ experiment) or ozone (for the $\alpha$-pinene $+\mathrm{O}_{3}+\mathrm{CO}$ experiment) concentrations (Table 2). The simulations were performed with environmental parameters (temperature, relative humidity and dilution rate) averaged over each experiment duration, these parameters varying minimally. The chamber mixture is diluted during the experiment because of the periodical introductions of purified air in the chamber to compensate for losses from analytical sampling and also through leakage. The dilution rate was determined by following $\mathrm{SF}_{6}$ concentration during each experiment as measured by FT-IR (Fourier Transform InfraRed), and was well described by a single first order decay (Table 2). Aerosol formed during an experiment is affected by both dilution and by depositional losses onto the chamber surfaces.
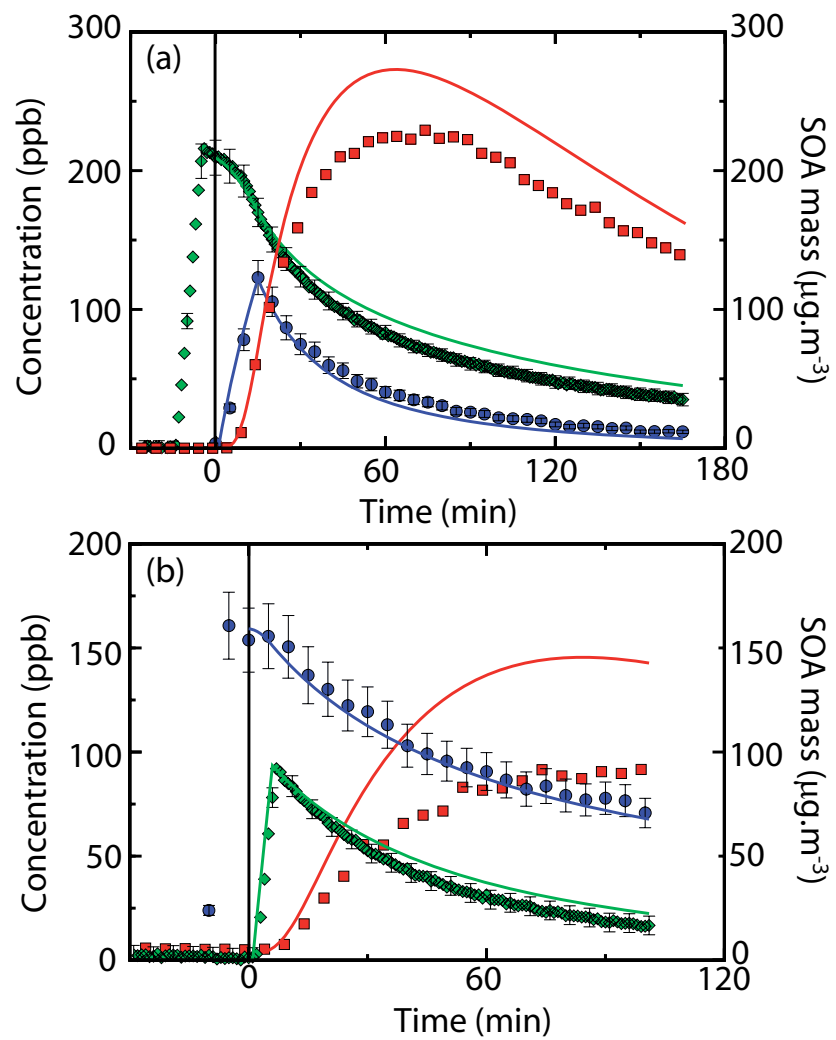

Fig. 3. Temporal profile of SOA mass (red), $\alpha$-pinene (blue) and $\mathrm{O}_{3}$ (green) during the $\alpha$-pinene $+\mathrm{O}_{3}$ (a) and the $\alpha$ pinene $+\mathrm{O}_{3}+\mathrm{CO}$ (b) EUPHORE experiments. Lines are the simulated results.

Both processes were combined into a global first-order loss with no dependence on aerosol size. At the end of each experiment, the majority ( $>80 \%$ ) of the precursor ( $\alpha$-pinene) was consumed and the particle size distribution of the aerosol remained unchanged. We assume that at this point, dilution and wall loss of particles were the dominant processes affecting SOA evolution. The aerosol loss rate was calculated from the decay of the total particle volume concentration at this point, prior to starting SOA filter collection.

\section{Temporal profile of SOA mass}

The simulated temporal profile of SOA mass is compared with that observed in Fig. 3 for the $\alpha$-pinene+ $\mathrm{O}_{3}$ and $\alpha$-pinene $+\mathrm{O}_{3}+\mathrm{CO}$ EUPHORE experiments. The observed SOA mass concentration was determined assuming an aerosol density of $1.2 \mathrm{~g} \mathrm{~cm}^{-3}$, as measured previously for SOA from $\alpha$-pinene ozonolysis (e.g. Zelenyuk et al., 2008). The temporal evolution of the precursors $\left(\alpha\right.$-pinene and $\left.\mathrm{O}_{3}\right)$ is also shown. The simulated $\alpha$-pinene concentration differs by less than $10 \mathrm{ppb}$ from the observations. The ozone decay is however underestimated, especially for the experiment performed without a scavenger, with a maximum difference 
in $\mathrm{O}_{3}$ concentrations of $20 \mathrm{ppb}$. A rapid formation of $\mathrm{SOA}$ is observed as soon as the $\alpha$-pinene is oxidized. SOA mass maxima of 230 and $90 \mu \mathrm{g} \mathrm{m}^{-3}$ were observed for the $\alpha$ pinene $+\mathrm{O}_{3}$ and $\alpha$-pinene $+\mathrm{O}_{3}+\mathrm{CO}$ experiments after approximately 60 and $90 \mathrm{~min}$, respectively. The simulated temporal profile of SOA mass is relatively well captured by the model both in terms of the shape and the magnitude. The modelled formation of SOA starts as soon as the simulation begins to reach a maximum after $\sim 60$ and $\sim 80 \mathrm{~min}$ for the $\alpha$ pinene $+\mathrm{O}_{3}$ and the $\alpha$-pinene $+\mathrm{O}_{3}+\mathrm{CO}$ experiments, respectively, which is temporally similar to the observed maxima. The maximum SOA mass concentration is overestimated by the model by around $40 \mu \mathrm{g} \mathrm{m}^{-3}(17 \%)$ and $55 \mu \mathrm{g} \mathrm{m}^{-3}(61 \%)$ for the $\alpha$-pinene $+\mathrm{O}_{3}$ and $\alpha$-pinene $+\mathrm{O}_{3}+\mathrm{CO}$ experiments respectively. For these two $\alpha$-pinene experiments, the model simulates the observed SOA mass within a factor of 2 . While this represents a good model performance, it is important to note the significant uncertainties inherent in the comparison of the measured and modelled SOA mass curves shown in Fig. 3:

- Vapour pressure estimation method. The Myrdal and Yalkowsky method coupled to the Joback estimates has recently been shown to systematically underestimate vapour pressures compared with experimental data, for a range of atmospherically relevant SVOC (Barley and McFiggans, 2010). The implementation of an alternative method to estimate vapour pressures would lead to different, potentially significantly lower, modelled SOA mass. A sensitivity study investigating the impact of vapour pressure estimates is presented in Sect. 4.2.

- Micro-physical processes. No diffusion limitations or nucleation processes were implemented within the model. This therefore implicitly assumes that these processes are not rate-limiting. In addition, potential SVOC loss to particles deposited on the chamber walls is not considered (Hildebrant et al., 2009). However, the loss of SVOC to the walls of the EUPHORE chamber is expected to be small considering the low surface/volume ratio $\left(\sim 0.75 \mathrm{~m}^{-1}\right)$ involved and in comparison to (modelled) losses from the dilution processes.

- Errors and omissions in the gas-phase chemical scheme (MCM). The MCM is a near-explicit chemical mechanism, necessarily incorporating some systematic mechanistic simplifications (for example, lumping of the organic peroxy-radical self and cross-reactions). Large uncertainties also exist with regard to the degradation chemistry of bi- and multi-functional oxygenated products. The MCM is likely to omit several "novel" degradation pathways for $\alpha$-pinene. For example, theoretical calculations have shown that peroxy and alkoxy radicals formed during $\alpha$-pinene oxidation could evolve by isomerisation leading to the formation of low volatility species (e.g. Peeters et al., 2001; Fantechi et al., 2002;
Vereecken and Peeters, 2004; Vereecken et al., 2007). These pathways are not currently implemented in the MCMv3.1, and will lead to increase gas-phase SVOC formation and hence the simulated SOA mass. Such SVOC would also be expected to contribute to the observed gas- and condensed-phase mass spectra, and are considered in the context of the observed mass spectra in Sect. 5.2. Similarly, further oxidation steps of other minor product channels (not incorporated into the MCM scheme) could influence the gaseous formation of SVOC (e.g. Camredon et al., 2007). The use of a fully explicit mechanism to describe $\alpha$-pinene oxidation would likely increase the formation of SVOC and therefore the simulated SOA mass.

- Condensed phase reactivity. The implementation of condensed phase reactions, or heterogeneous reactions between the aerosol and gaseous (S)VOC, would be expected to enhance the uptake of SVOC into the condensed phase and hence increase the simulated SOA mass. A sensitivity study to explore this possibility is described Sect. 4.1.

\subsection{Condensed phase reactivity}

No condensed phase reaction was considered in the model. If we assume that the products of any condensed phase reaction are less volatile than their precursor reactants, the aerosol mass simulated here can be seen as a lower limit (e.g. Kroll and Seinfeld, 2008), all other factors (including vapour pressure estimation method) not withstanding. In order to assess the influence of SVOC reactivity in the condensed phase on SOA mass, a sink of condensed SVOC was implemented in the model. Each condensed SVOC, SVOC ${ }_{i}^{(a)}$, was considered to follow a pseudo first order loss process with a kinetic constant $k_{\text {react }}^{(\mathrm{a})}$, leading to the formation of a non-volatile organic species, nvoc:

$\mathrm{SVOC}_{i}^{(\mathrm{a})} \rightarrow$ nvoc.

This non-volatile organic species, nvoc, was considered to remain in the condensed phase and to be inert chemically, representing a permanent sink of SVOC to the condensed phase. This loss process of each condensed SVOC was implemented in the box model at the same time step as the gas/particle partitioning processes of each organic, i.e. with an operator time step of $1 \mathrm{~min}$. Simulations were performed considering a chemical lifetime for condensed $\operatorname{SVOC}\left(\tau_{\text {react }}^{(\mathrm{a})}=1 / k_{\text {react }}^{(\mathrm{a})}\right)$ of 60,30 and $5 \mathrm{~min}$. The temporal profiles of these simulated SOA masses are also shown in Fig. 5a and b. As expected, the addition of a sink of SVOC in the condensed phase enhances the uptake of organics to the aerosol within simulated SOA mass. The simulated SOA maximum is increased by $35(13 \%), 60(22 \%)$ and $130 \mu \mathrm{m}^{-3}(48 \%)$ during the $\alpha$-pinene $+\mathrm{O}_{3}$ experiment and by $40(28 \%), 60(41 \%)$ 
and $95 \mu \mathrm{g} \mathrm{m}^{-3}(66 \%)$ during the $\alpha$-pinene+ $\mathrm{O}_{3}+\mathrm{CO}$ experiment, in comparison with the SOA maximum simulated with no condensed phase reactivity, for $\tau_{\text {react }}^{(a)}=60,30$ and $5 \mathrm{~min}$ respectively. Generally, assuming the condensed phase lifetime of SVOC is of the order of $5 \mathrm{~min}$ or longer, the implementation of condensed phase reactions in the model would increase the simulated SOA mass by less than a factor of 2 .

\subsection{Vapour pressure estimates}

The results of this study may be compared with that of Jenkin (2004), in which the MCM was used to simulate SOA formation during $\alpha$-pinene chamber ozonolysis experiments, performed under environmental conditions similar to this work. In the earlier study, negligible SOA concentrations were simulated in comparison with experiment, unless the equilibrium constants for gas/particle partitioning were increased by two orders of magnitude. Our approach differs from that of Jenkin (2004) in the method adopted to estimate the vapour pressures of SVOC. Jenkin (2004) have estimated the vapour pressure using a modified form of the Mackay method (Mackay et al., 1982) coupled with the Stein and Brown structure/property relationship (Stein and Brown, 1994) for boiling point estimates.

Figure 4 shows comparisons between vapour pressures estimated at $298 \mathrm{~K}$ in this study (i.e. with the Myrdal and Yalkowsky method combined with the Joback method for boiling points estimates, vapour pressure estimates referenced hereafter as $\left.P_{\mathrm{M} \& \mathrm{Y}, \mathrm{J}}^{\mathrm{vap}}\right)$ with those estimated by Jenkin (2004) (i.e. with the modified Mackay method combined with the Stein and Brown method for boiling points estimates, vapour pressure estimates referenced hereafter as $P_{\mathrm{mM}, \mathrm{S} \& \mathrm{~B}}^{\mathrm{vap}}$ ) for a range of secondary species formed during $\alpha$-pinene oxidation, together with two other combinations: vapour pressures estimated using the Myrdal and Yalkowsky method coupled with the Stein and Brown method and using the modified Mackay coupled with the Joback method (vapour pressure estimates hereafter referenced as $P_{\mathrm{M} \& \mathrm{Y}, \mathrm{S} \& \mathrm{~B}}^{\mathrm{vap}}$ and $P_{\mathrm{mM}, \mathrm{J}}^{\mathrm{vap}}$ respectively). For this specific set of compounds, the $P_{\mathrm{M} \& \mathrm{Y}, \mathrm{J}}^{\mathrm{va}}$ vary over a large range, between around $10^{-3}$ to $10^{-13} \mathrm{~atm}$. The $P_{\mathrm{mM}, \mathrm{S} \& \mathrm{~B}}^{\mathrm{vap}}$ are higher than the $P_{\mathrm{M} \& \mathrm{Y}, \mathrm{J}}^{\mathrm{vap}}$, with divergence between $P_{\mathrm{M} \& \mathrm{Y}, \mathrm{J}}^{\mathrm{vap}}$ and $P_{\mathrm{mM}, \mathrm{S} \& \mathrm{~B}}^{\mathrm{vap}}$ of between 3 and 5 orders of magnitude for the "top ten" species simulated to have a dominant contribution to SOA formed under the conditions of the $\alpha$-pinene $+\mathrm{O}_{3}$ EUPHORE experiment (open circles in Fig. 4). The use of $P_{\mathrm{mM}, \mathrm{S} \& \mathrm{~B}}^{\mathrm{vap}}$ in the SOA model employed in this work leads to zero SOA formation for the $\alpha$-pinene $+\mathrm{O}_{3}$ and $\alpha$-pinene $+\mathrm{O}_{3}+\mathrm{CO}$ EUPHORE experiments, in agreement with the findings of Jenkin (2004). The use of $P_{\mathrm{M} \& \mathrm{~V}, \mathrm{~S} \& \mathrm{~B}}$ in the model leads also to zero SOA formation. The use of $P_{\mathrm{mM}, \mathrm{J}}^{\mathrm{vap}}$ leads to an SOA maximum of approximately a factor of two lower than that obtained with $P_{\mathrm{M} \& \mathrm{Y}, \mathrm{J}}^{\mathrm{vap}}$

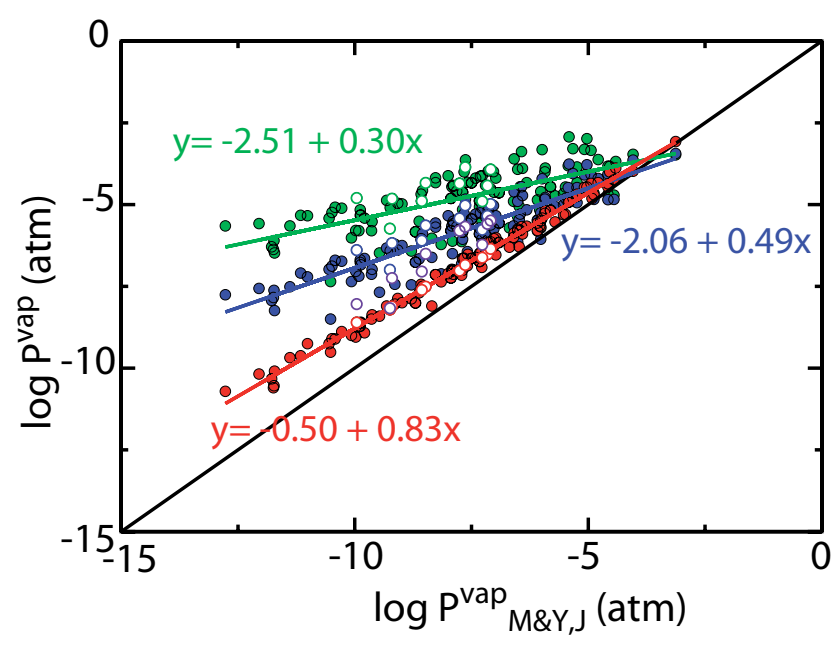

Fig. 4. $P_{\mathrm{mM}, \mathrm{S} \& \mathrm{~B}}^{\mathrm{vap}}$ (green, Jenkin method), $P_{\mathrm{M} \& \mathrm{Y}, \mathrm{S} \& \mathrm{~B}}^{\mathrm{vap}}$ (blue), $P_{\mathrm{mM}, \mathrm{J}}^{\mathrm{vap}}\left(\right.$ red) and $P_{\mathrm{N}, \mathrm{N}}^{\mathrm{vap}}$ (purple) versus $P_{\mathrm{M} \& \mathrm{Y}, \mathrm{J}}^{\mathrm{vap}}$ (this work) at $298 \mathrm{~K}$ for secondary species formed during $\alpha$-pinene oxidation, plus regression lines and $\mathrm{x}=\mathrm{y}$ line (black). The ten species simulated to have a dominant contribution in mass to SOA formed during the $\alpha$-pinene $+\mathrm{O}_{3}$ EUPHORE experiment are shown in white (MCM names: C107OH, APINBOH, C98OOH, C107OOH, C97OOH, APINAOOH, PINONIC, PINIC, C108OOH, C108OH).

Recently, Barley and McFiggans (2010) have shown that the Myrdal and Yalkowsky method coupled with the Joback method for estimating boiling points significantly underestimates vapour pressures for a range of atmospherically relevant SVOC, and suggest that the Nannoolal methods for vapour pressure (Nannoolal et al., 2008) and boiling point (Nannoolal et al., 2004) estimation would provide more reliable results for SOA calculations. The $298 \mathrm{~K}$ vapour pressures for the "top ten" species in $\alpha$-pinene oxidation estimated using the Nannoolal methods (referenced hereafter as $P_{\mathrm{N}, \mathrm{N}}^{\mathrm{vap}}$ ) are shown in Fig. 4. For these species, the $P_{\mathrm{N}, \mathrm{N}}^{\mathrm{vap}}$ are systematically higher than the $P_{\mathrm{M} \& \mathrm{Y}, \mathrm{J}}^{\mathrm{vap}}$, with divergences varying between a factor of 10.9 and 94.4 , highlighting that the choice of vapour pressure estimation method is a critical factor in simulating SOA formation. Simulations performed with an increase of all vapour pressures $\left(P_{\mathrm{M \& Y}, \mathrm{J}}^{\mathrm{vap}}\right)$ by factors of 10 and 100 in the SOA model, encompassing the range of vapour pressure scale factors found between $P_{\mathrm{N}, \mathrm{N}}^{\mathrm{vap}}$ and $P_{\mathrm{M} \& \mathrm{Y}, \mathrm{J}}^{\mathrm{vap}}$, are shown in Fig. 5. An increase of all $P_{\mathrm{M} \& \mathrm{Y}, \mathrm{J}}^{\mathrm{va}}$ by factors of 10 and 100 leads to SOA maxima which are factors of 2 and 6 respectively lower than that obtained with $P_{\mathrm{M} \& \mathrm{Y}, \mathrm{J}}^{\mathrm{vap}}$ for the $\alpha$-pinene $+\mathrm{O}_{3}$ experiment. The influence of vapour pressure is higher for the $\alpha$-pinene+ $\mathrm{O}_{3}+\mathrm{CO}$ experiment, with SOA maxima which are factors of 8 and 30 respectively lower than that obtained with $P_{\mathrm{M} \& \mathrm{Y}, \mathrm{J}}^{\mathrm{vap}}$. In this experiment, the formation of SOA comes from first generation oxidation products from $\alpha$-pinene ozonolysis, as $\mathrm{OH}$ radicals are scavenged by $\mathrm{CO}$. Therefore the simulated SOA formation shows a large sensitivity to the vapour pressure 

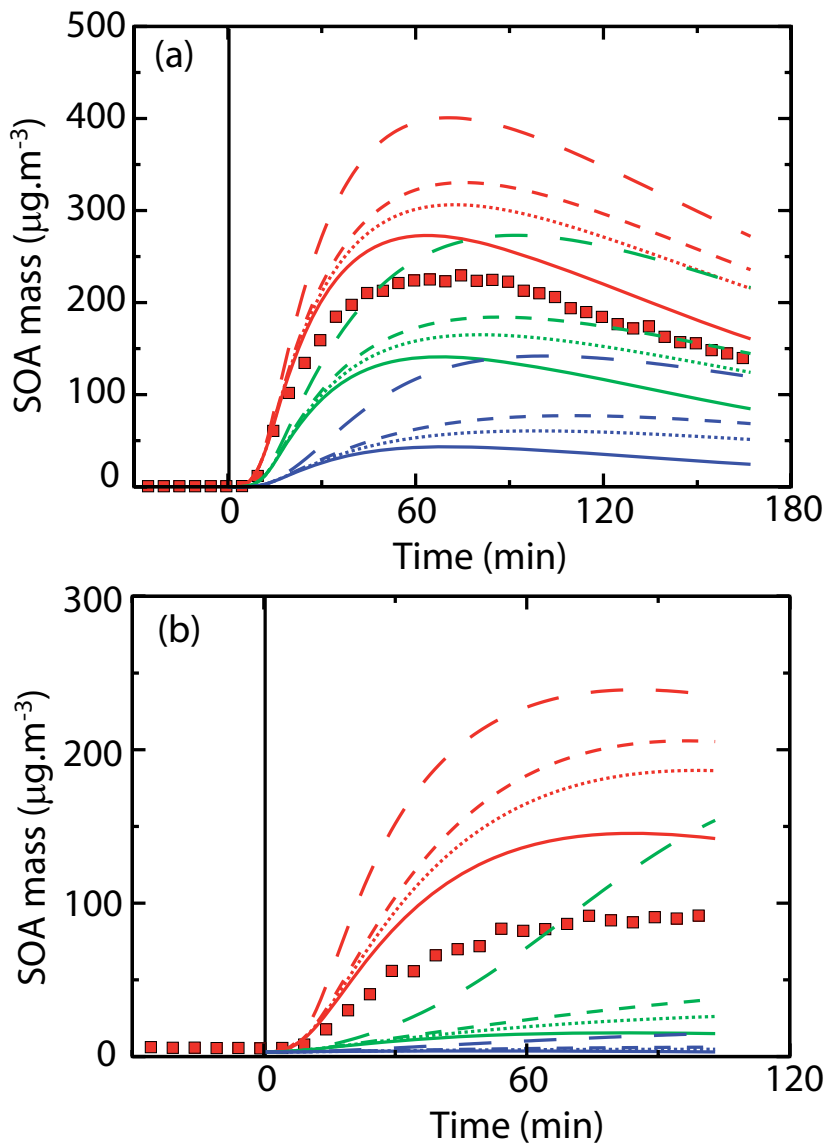

Fig. 5. Temporal profile of SOA mass (red squares), during the $\alpha$-pinene $+\mathrm{O}_{3}$ (a) and the $\alpha$-pinene $+\mathrm{O}_{3}+\mathrm{CO}$ (b) EUPHORE experiments. Lines are the simulated results with vapour pressures estimated with $P_{\mathrm{M} \& \mathrm{Y}, \mathrm{J}}^{\mathrm{vap}}$ (red), $P_{\mathrm{M} \& \mathrm{Y}, \mathrm{J}}^{\mathrm{vap}}$ multiplied by 10 (green) and 100 (blue). Dotted, small-dashed and large-dashed lines are the simulated SOA mass considering a condensed SVOC lifetime of 60,30 and $5 \mathrm{~min}$ respectively.

of these compounds. In all cases, an increase of $P_{\mathrm{M} \& \mathrm{Y}, \mathrm{J}}^{\mathrm{vap}}$ values leads to a substantial underestimate of SOA mass in comparison to measurements. This underestimate could be ameliorated if additional reaction pathways forming SVOC (not included in the MCMv3.1) were to occur, and/or by condensed phase oligomerisation reactions. Figure 5 also shows the impact of implementing condensed phase reactivity (as described Sect. 4.1) within the simulation, with assumed lifetimes of 60, 30 and $5 \mathrm{~min}$ for condensed phase species. Other uncertainties notwithstanding, a lifetime for SVOC in the condensed phase of the order of $5 \mathrm{~min}$ is required to bring the simulated SOA mass into agreement with the observed levels.

\section{Distribution of gaseous and particulate organics}

SOA formation from $\alpha$-pinene ozonolysis was studied with a particular focus on the distribution of gaseous and particulate organic compounds. The organic speciation is illustrated here with modelled versus measured comparisons performed for the $\alpha$-pinene+ $\mathrm{O}_{3}$ EUPHORE experiment.

\subsection{Gaseous phase VOC and SVOC}

\subsubsection{The observed CIR-TOF-MS mass spectrum}

The distribution of gaseous organics was monitored using CIR-TOF-MS. Details of the instrument are given in Blake et al. (2004) and Wyche et al. (2007), hence only salient points required to interpret the CIR-TOF-MS $\mathrm{m} / \mathrm{z}$ spectra are presented here. During the current experiments, sample air from the EUPHORE chamber was delivered continuously to the CIR-TOF-MS through a heated $50 \mathrm{~cm}$ long Teflon sampling line. Once within the instrument, the analyte molecules underwent chemical ionization via reaction with the hydronium ion, $\mathrm{H}_{3} \mathrm{O}^{+}$. Using this method the reagent reacts with the analyte, $\mathrm{R}$, via direct proton transfer to form a positively charged ion $\mathrm{RH}^{+}$:

$\mathrm{H}_{3} \mathrm{O}^{+}+\mathrm{R} \rightarrow \mathrm{RH}^{+}+\mathrm{H}_{2} \mathrm{O}$.

The proton addition occurs predominantly at the site of highest electronic density on the analyte, i.e. in order: acid, ketone, aldehyde, alcohol and hydroperoxide functional groups, for moieties of relevance to tropospheric oxidation (Blake et al., 2009). Once formed the $\mathrm{RH}^{+}$ion can undergo fragmentation to produce an ionised daughter fragment $\left(\mathrm{F}^{+}\right)$ and a neutral molecule (N) (McLafferty and Turecek, 1993):

$\mathrm{RH}^{+} \rightarrow \mathrm{F}^{+}+\mathrm{N}$

For molecules containing acid, aldehyde and/or alcohol functionalities, the most common fragmentation mechanism following proton transfer ionisation is water elimination (Smith and Spanel, 2005), e.g. for an alcohol ROH:

$(\mathrm{ROH}) \mathrm{H}^{+} \rightarrow \mathrm{R}^{+}+\mathrm{H}_{2} \mathrm{O}$.

Following ionisation, analyte ions are accelerated by an electric field into a time-of-flight mass spectrometer for analysis. The analyte $\mathrm{R}$ is then observed in its protonated form $\left(m / z[\mathrm{M}+1]^{+}\right.$, where $\mathrm{M}$ is the molar mass of the analyte $\left.\mathrm{R}\right)$ and frequently, in the case of oxygenated compounds, also at the $m / z$ of its dehydrated form $\left(m / z[(\mathbf{M}+1)-18]^{+}\right)$and/or at the $m / z$ of its fragment ions, the most common being the allyl ion $\left(\mathrm{CH}_{2}=\mathrm{CHCH}_{2}^{+}, m / z 41\right)$, the n-propyl ion $\left(\mathrm{CH}_{3} \mathrm{CH}_{2} \mathrm{CH}_{2}^{+}\right.$, $m / z 43)$ or the acetyl ion $\left(\mathrm{CH}_{3} \mathrm{CO}^{+}, \mathrm{m} / z\right.$ 43) (Wyche et al., 2005; Blake et al., 2006). The relative contribution of $\mathrm{RH}^{+}$ and the various fragments $i, \mathrm{~F}_{i}^{+}$, to the total signal is species dependent. The extent of fragmentation tends to increase 
Table 3. Characterized CIR-TOF-MS signatures for species of interest for $\alpha$-pinene oxidation. The $\mathrm{m} / z$ of fragments ions and their relative abundances to the total signal have been identified by CIR-TOF-MS calibration ${ }^{(1)}$ and from literature Hellen et al. $(2008)^{(2)}$. RA indicates relative abundance.

\begin{tabular}{lrrrl}
\hline & $\begin{array}{r}\text { Molar } \\
\text { mass }\end{array}$ & $\begin{array}{r}\mathrm{RH}^{+} \\
(\mathrm{RA})\end{array}$ & $\begin{array}{l}\mathrm{RH}^{+}-\mathrm{H}_{2} \mathrm{O} \\
(\mathrm{RA})\end{array}$ & $\begin{array}{l}\mathrm{F}_{i}^{+} \\
(\mathrm{RA})\end{array}$ \\
\cline { 3 - 5 }$\left(\mathrm{g} \mathrm{mol}^{-1}\right)$ & 136 & $137(40 \%)$ & & $81(60 \%)$ \\
$\alpha$-pinene $^{(1)}$ & 184 & $185(5 \%)$ & $167(16 \%)$ & $139(6 \%), 115(32 \%), 71(34 \%), 69(7 \%)$ \\
pinonic acid $^{(2)}$ & 168 & $169(8 \%)$ & $151(34 \%)$ & $123(3 \%), 109(7 \%), 108(4 \%), 107(44 \%)$ \\
pinonaldehyde $^{(1)}$ & 152 & $153(8 \%)$ & $135(50 \%)$ & $109(26 \%), 107(5 \%), 93(11 \%)$ \\
pinene oxide $^{(1)}$ & 60 & $61(100 \%)$ & & \\
acetic acid $^{(1)}$ & 58 & $59(100 \%)$ & & \\
acetone $^{(1)}$ & 46 & $47(100 \%)$ & & \\
formic acid $^{(1)}$ & 44 & $45(100 \%)$ & & \\
acetaldehyde $^{(1)}$ & 32 & $33(100 \%)$ & & \\
methanol $^{(1)}$ & 30 & $31(100 \%)$ & & \\
formaldehyde $^{(1)}$ & & & & \\
\hline
\end{tabular}

with the length of the carbon chain. Characterized CIR-TOFMS mass spectral signatures for a number of species of interest for $\alpha$-pinene oxidation are listed in Table 3. The mass resolution $(\mathrm{m} / \Delta \mathrm{m})$ of the CIR-TOF-MS during the current experiments was around 1500. The CIR-TOF-MS spectra presented here were normalized to $10^{6} \mathrm{H}_{3} \mathrm{O}^{+}$ion counts, background subtracted and averaged over $10 \mathrm{~min}$ (Blake et al., 2004).

\subsubsection{The simulated gaseous mass spectrum}

A direct comparison of the simulated gaseous concentrations with the CIR-TOF-MS mass spectrum is difficult owing to the presence of numerous fragment ions in the spectrum. A simplified representation of this fragmentation has been considered to create a "simulated gaseous mass spectrum". The simulated gaseous mass spectrum has been constructed as follows:

1. $m / z$ peaks for each species $\mathrm{R}$ :

ions considered were $\mathrm{RH}^{+}$giving a $m / z[\mathrm{M}+1]^{+}$peak, and in some cases fragmented forms, such as $\mathrm{RH}^{+}-\mathrm{H}_{2} \mathrm{O}$ giving a $m / z[(\mathrm{M}+1)-18]^{+}$peak and/or other $\mathrm{F}_{i}^{+}$fragments giving a peak at their corresponding $m / z$ through the following assumptions. For compounds having a characterized CIR-TOF-MS signature the relative contribution of each $\mathrm{m} / \mathrm{z}$ peak was used, as given in Table 3 . For other compounds it has been assumed that (1) protonated species having a chain length shorter than or equal to 3 carbons do not fragment and (2) protonated species containing an acid, aldehyde or alcohol moiety (following the acid, ketone, aldehyde, alcohol, hydroperoxide priority order for the protonated site on a multifunctional species) dehydrate at a value of $40 \%$ (representative of the known fragmentation fractions; see Table 3).
No fragmentation was considered for the other compounds;

2. Intensity of the $m / z$ peaks for each species R:

the intensity of each $\mathrm{m} / \mathrm{z}$ peak was assumed to be proportional to the simulated gaseous concentration of the species R scaled by their relative contribution;

3. Total $\mathrm{m} / \mathrm{z}$ intensity at a resolution of $1 \mathrm{Da}$ : the total intensity of each integer $\mathrm{m} / \mathrm{z}$ peak was calculated by summing the intensities of all the ions between $m / z-0.5$ and $m / z+0.5$.

It is important to note that for compounds which do not have characterised fragmentation patterns (i.e. the majority of secondary species), this approach neglects fragments other than dehydrated ions of the protonated analyte. Furthermore, this method considers that the simulated signal intensity is proportional to the concentration, independent of the species, whereas in practice each species has a different ionisation efficiency, and hence a different CIR-TOF-MS response. In addition, the fraction of the analyte that dehydrates is fixed at $40 \%$, a value that in reality is likely to differ significantly between species (Smith and Spanel, 2005). A quantitative comparison between the simulated and CIR-TOF-MS signal intensity is therefore not possible, but a qualitative comparison with the observations may be made.

\subsubsection{Comparison of the gaseous mass spectra}

The simulated gaseous mass spectrum is compared with the observed CIR-TOF-MS mass spectrum in Fig. 6 for scans recorded and simulated after $60 \mathrm{~min}$ reaction time (i.e. at peak SOA loading, see Fig. 3). The CIR-TOF-MS mass spectrum is shown on the upper $y$-axis. Around 35 peaks showing 
the temporal signal of secondary species (products) formed during the experiment were recorded in the mass spectra between $\mathrm{m} / \mathrm{z} 0$ and $300 \mathrm{Da}$. The simulated gaseous mass spectrum is plotted on the lower y-axis. A total of 37 peaks, of which 26 represent non fragmented ions $\left(\mathrm{RH}^{+}\right)$, were simulated by the model in the mass range $m / z 0-300 \mathrm{Da}$. The close correspondence between many of the observed and simulated peaks indicates that the mass distribution of the major products is reasonably well reproduced. In the higher mass range $(\mathrm{m} / \mathrm{z}>100 \mathrm{Da})$, most of the peaks recorded by the CIR-TOFMS are also present in the simulated $\mathrm{m} / z$ spectra. Some simulated peaks are not detected by the CIR-TOF-MS (such as $m / z 201,189,187,175$ or 159$)$. In the lower mass range $(\mathrm{m} / z<100 \mathrm{Da})$, most of the observed peaks are not present in the simulation. These signals (such as at $m / z$ 43, 93, 95 or 99) are likely to be fragment ions that are not considered in our simple fragmentation approach.

Species have been assigned to the major peaks detected by the CIR-TOF-MS on the basis of characterized CIRTOF-MS signatures (see Table 3) and previous identification of secondary products formed from $\alpha$-pinene oxidation (e.g. Yu et al., 2008). The proposed structures for these major compounds are shown in Table 4. Their simulated temporal evolution is compared with the CIRTOF-MS measurements in Fig. S1 of the Supplementary material: http://www.atmos-chem-phys.net/10/2893/2010/ acp-10-2893-2010-supplement.pdf. The main peaks arise from formaldehyde $(\mathrm{m} / \mathrm{z} 31)$, formic acid $(\mathrm{m} / \mathrm{z}, 47)$, acetone $(\mathrm{m} / \mathrm{z}, 59)$, acetic acid $(\mathrm{m} / \mathrm{z}, 61), \alpha$-pinene $(\mathrm{m} / \mathrm{z}, 137,81)$ and pinonaldehyde $(m / z, 169,151,109,107)$. The simulated peaks for many of these major observed $\mathrm{m} / \mathrm{z}$ signals are consistent with the CIR-TOF-MS measurements (see Fig. 6a), and their simulated temporal evolutions are in good agreement with the CIR-TOF-MS observations (see Fig. S1: http://www.atmos-chem-phys.net/10/2893/2010/ acp-10-2893-2010-supplement.pdf). The exceptions concern the $m / z$ of acetic acid which has a high intensity in the CIR-TOF-MS signal but is simulated to be formed at very low concentration, and formic acid which is not produced in the simulation. Formic and acetic acids signals present within the measurements are most likely a result of off-gassing from the chamber walls, which is often observed with such experiments (e.g. Rickard et al., 2009); such reactions are not represented in our chamber mechanism. It should also be noted that other larger molecular weight species can produce fragment ions of $\mathrm{m} / \mathrm{z} 61$ using the proton transfer technique. The simulated contribution of the identified compounds to the total concentration of gaseous species at a given molar mass $\left( \pm 0.5 \mathrm{~g} \mathrm{~mol}^{-1}\right)$ is also given in Table 4 . These assigned compounds are calculated to make a dominant contribution $(>70 \%)$ to their mass channel, indicating that the assigned species are the main product found at these $m / z$. However other species detectable by CIR-TOFMS could also potentially contribute to an observed $\mathrm{m} / \mathrm{z}$ peak. For example, glycolaldehyde is simulated to contribute $27 \%$
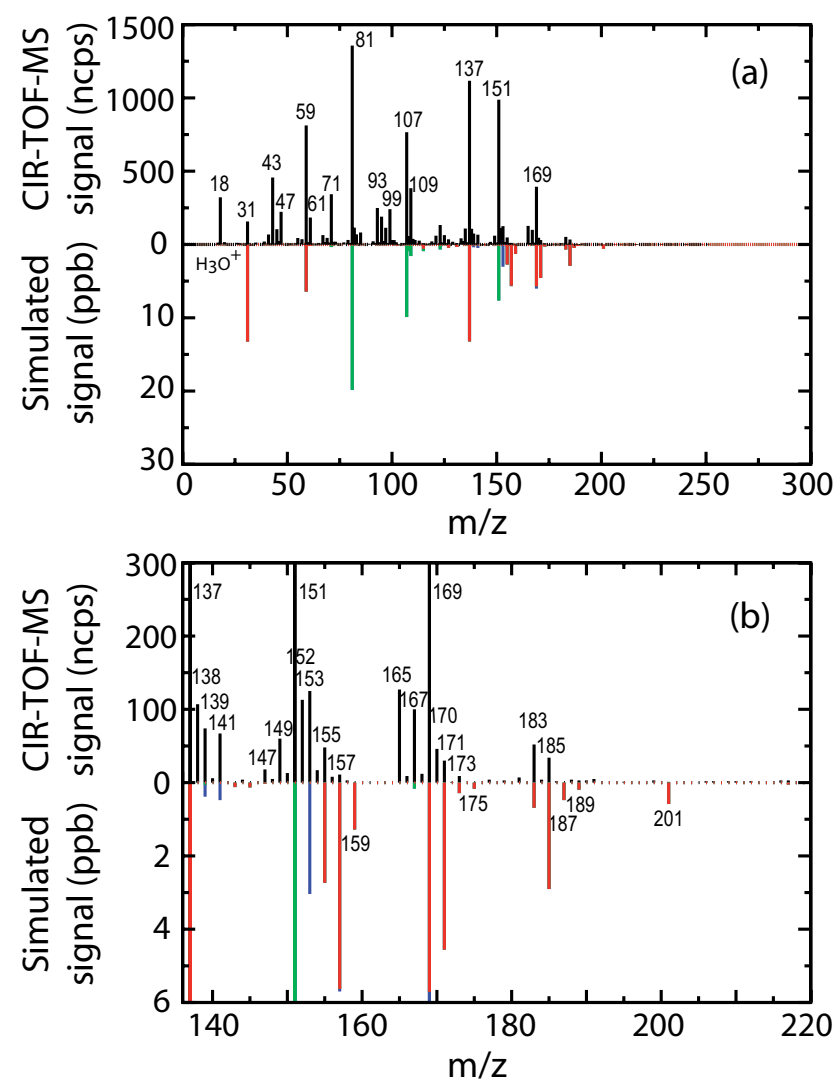

Fig. 6. Gaseous $m / z$ spectra of the $\alpha$-pinene+O $\mathrm{O}_{3}$ EUPHORE experiment: (a) whole spectrum between 1 and $300 \mathrm{Da}$ and (b) zoom between 137 and $220 \mathrm{Da}$. The CIR-TOF-MS mass spectrum recorded after $60 \mathrm{~min}$ of experiment is shown in the upper $\mathrm{y}$-axis. Labels show the $m / z$, value for the most intense peaks. The simulated gaseous mass spectrum at the same oxidation time is shown in the lower y-axis. The red bars are the simulated $\mathrm{m} / \mathrm{z}$ signals associated with the (parent) $\mathrm{RH}^{+}$ions. The green bars and blue bars are the simulated $\mathrm{m} / \mathrm{z}$, signals associated with the fragment ions for species having characterized and uncharacterized signatures respectively. Labels in the lower mass spectrum indicate the $\mathrm{m} / \mathrm{z}$, values of simulated peaks which are not detected by the CIR-TOF-MS.

of the total concentration at $m / z 61$ compared with $73 \%$ from acetic acid, and 2-hydroxopinan-3-one which is simulated to contribute $15 \%$ to the total concentration at $\mathrm{m} / \mathrm{z} .169 \mathrm{com}-$ pared with $85 \%$ from pinonaldehyde.

Apart from pinonaldehyde, the major peaks present in the CIR-TOF-MS spectrum correspond to volatile species. Gaseous SVOC, of low volatility and hence most important for SOA formation, are generally expected to have a higher molecular weight and therefore are to be found at higher $m / z$. Figure $6 \mathrm{~b}$ focuses on the gaseous mass spectrum for $m / z$ greater than the protonated $\alpha$-pinene ion $\left(\mathrm{RH}^{+}\right.$ at $\mathrm{m} / \mathrm{z}$ 137). Structures for the gaseous SVOC detected by the CIR-TOF-MS have been suggested on the basis of the simulated speciation, and are shown in Table 4 together 
Table 4. Proposed structures for the major compounds (based on previous identifications) and SVOC (based on the simulation) detected by the CIR-TOF-MS during the $\alpha$-pinene+O ${ }_{3}$ EUPHORE experiment together with their simulated contribution to the total concentration of gaseous species having the same molar mass (within $\pm 0.5 \mathrm{~g} \mathrm{~mol}^{-1}$ ).

\begin{tabular}{|c|c|c|c|c|c|}
\hline $\begin{array}{c}\boldsymbol{m} / \mathbf{z} \\
\left([\mathrm{R}+\mathrm{H}]^{+}, \mathrm{F}^{+}\right)\end{array}$ & $\begin{array}{c}\text { Molar mass } \\
\left(\mathrm{g} \mathrm{mol}^{-1}\right)\end{array}$ & Name/Molecular formula & Structure & MCM name & $\begin{array}{c}\text { Simulated } \\
\text { contribution }\end{array}$ \\
\hline \multicolumn{6}{|c|}{ Major compounds } \\
\hline $\begin{array}{l}169,151 \\
109,107\end{array}$ & 168.23 & pinonaldehyde & & PINAL & $85 \%$ \\
\hline 137,81 & 136.23 & $\alpha$-pinene & & APINENE & $100 \%$ \\
\hline 99 & & common fragment ion & & & \\
\hline 93 & & common fragment ion & & & \\
\hline 71 & & pinonic acid $F_{i}^{+}$ & & & \\
\hline 61 & 60.05 & acetic acid & & $\mathrm{CH} 3 \mathrm{CO} 2 \mathrm{H}$ & $73 \%$ \\
\hline 59 & 58.10 & acetone & & $\mathrm{CH} 3 \mathrm{COCH} 3$ & $97 \%$ \\
\hline 47 & 46.03 & formic acid & & $\mathrm{HCOOH}$ & $100 \%$ \\
\hline 43 & & common fragment ion & & & \\
\hline 31 & 30.03 & formaldehyde & $0=$ & $\mathrm{HCHO}$ & $100 \%$ \\
\hline \multicolumn{6}{|c|}{ Gaseous SVOC } \\
\hline \multirow[t]{2}{*}{185} & 184.23 & $\mathrm{C}_{10} \mathrm{H}_{16} \mathrm{O}_{3}$ & & $\mathrm{C} 107 \mathrm{OH}$ & $63 \%$ \\
\hline & 184.23 & pinonic acid & & PINONIC & $26 \%$ \\
\hline 183 & 182.22 & 4-oxo-pinonaldehyde & & $\mathrm{C} 109 \mathrm{CO}$ & $100 \%$ \\
\hline \multirow[t]{3}{*}{173} & 172.22 & $\mathrm{C}_{9} \mathrm{H}_{16} \mathrm{O}_{3}$ & & $\mathrm{C} 97 \mathrm{OH}$ & $57 \%$ \\
\hline & 172.22 & $\mathrm{C}_{9} \mathrm{H}_{16} \mathrm{O}_{3}$ & & $\mathrm{C} 96 \mathrm{OOH}$ & $42 \%$ \\
\hline & 172.18 & $\mathrm{C}_{8} \mathrm{H}_{12} \mathrm{O}_{4}$ & & NORPINIC & $<0.5 \%$ \\
\hline \multirow[t]{2}{*}{171} & 170.25 & 2,3-pinanediol & & APINBOH & $66 \%$ \\
\hline & 170.21 & $\mathrm{C}_{9} \mathrm{H}_{14} \mathrm{O}_{3}$ pinalic-3-acid & & $\mathrm{C} 89 \mathrm{CO} 2 \mathrm{H}$ & $33 \%$ \\
\hline \multirow[t]{2}{*}{$\begin{array}{l}170 \\
169\end{array}$} & 168.23 & $\begin{array}{l}\mathrm{m} / \mathrm{z} 169 \mathrm{C}_{13} \text { isotope } \\
\text { pinonaldehyde }\end{array}$ & & PINAL & $85 \%$ \\
\hline & 168.23 & 2-hydroxopinan-3-one & & APINBCO & $15 \%$ \\
\hline 167 & & pinonic acid $\mathrm{RH}^{+}-\mathrm{H}_{2} \mathrm{O}$ & & & \\
\hline 165 & & Absent in the simulation & & & \\
\hline \multirow[t]{3}{*}{157} & 156.22 & $\mathrm{C}_{9} \mathrm{H}_{16} \mathrm{O}_{2}$ & & $\mathrm{C} 96 \mathrm{OH}$ & $47 \%$ \\
\hline & 156.13 & $\mathrm{C}_{7} \mathrm{H}_{8} \mathrm{O}_{4}$ & & $\mathrm{CO} 235 \mathrm{C} 6 \mathrm{CHO}$ & $39 \%$ \\
\hline & 156.18 & $\mathrm{C}_{8} \mathrm{H}_{12} \mathrm{O}_{3}$ & & $\mathrm{C} 721 \mathrm{CHO}$ & $14 \%$ \\
\hline 155 & 154.21 & norpinonaldehyde & & NORPINAL & $100 \%$ \\
\hline 153 & & $\mathrm{~m} / z 171 \mathrm{RH}^{+}-\mathrm{H}_{2} \mathrm{O}$ & & & \\
\hline 152 & & $\begin{array}{l}\text { pinonaldehyde } \mathrm{RH}^{+}-\mathrm{H}_{2} \mathrm{O} \mathrm{C}_{13} \\
\text { isotope }\end{array}$ & & & \\
\hline 151 & & pinonaldehyde $\mathrm{RH}^{+}-\mathrm{H}_{2} \mathrm{O}$ & & & \\
\hline 149 & & Absent in the simulation & & & \\
\hline 147 & 146.14 & $\mathrm{C}_{6} \mathrm{H}_{10} \mathrm{O}_{4}$ & & $\mathrm{C} 614 \mathrm{OH}$ & $97 \%$ \\
\hline 141 & & $m / z 159 \mathrm{RH}^{+}-\mathrm{H}_{2} \mathrm{O}$ & & & \\
\hline 139 & & $\begin{array}{l}\text { pinonic acid } F_{i}^{+} \\
m / z 157 \mathrm{RH}^{+}-\mathrm{H}_{2} \mathrm{O}\end{array}$ & & & \\
\hline 138 & & $\alpha$-pinene $C_{13}$ isotope & & & \\
\hline 137 & 136.23 & $\alpha$-pinene & & & $100 \%$ \\
\hline
\end{tabular}


with their simulated contribution to the total concentration of gaseous species having the same molar mass (within $\pm 0.5 \mathrm{~g} \mathrm{~mol}^{-1}$ ). Their simulated temporal evolution is compared with the CIR-TOF-MS measurements in Fig. S2 of the Supplementary material: http://www.atmos-chem-phys. net/10/2893/2010/acp-10-2893-2010-supplement.pdf. The temporal profiles are comparable with the model predictions within the precision of the experimental data with the exception of $\mathrm{m} / z 147$ (see Fig. S2: http://www.atmos-chem-phys. net/10/2893/2010/acp-10-2893-2010-supplement.pdf), indicating that the principal species contributing to the observed peak of $\mathrm{m} / z 147$ may not be represented in the model. The simulated concentration at $\mathrm{m} / \mathrm{z}, 147$ is however very small and the observed signal could also be explained by the formation of species not included in the MCMv3.1 or by fragments of analytes formed during the CIR-TOF-MS analysis. Most of these species, such as pinonic acid $\left(\mathrm{RH}^{+}\right.$at $\left.\mathrm{m} / \mathrm{z} 185\right)$, 4-oxopinonaldehyde $\left(\mathrm{RH}^{+}\right.$at $\left.m / z 183\right)$, pinonaldehyde $\left(\mathrm{RH}^{+}\right.$at $m / z$ 169) and norpinonaldehyde $\left(\mathrm{RH}^{+}\right.$at $m / z$ 155) have been previously identified as secondary products formed during $\alpha$-pinene oxidation (e.g. Christoffersen et al., 1998; Yu et al., 1998, 1999, 2008; Glasius et al., 2000; Koch et al., 2000; Larsen et al., 2001; Lee et al., 2006; Ma et al., 2008). At the same mass channel as pinonic acid $\left(\mathrm{RH}^{+}\right.$at $m / z$ 185), an hydroxypinonaldehyde is simulated to have a large contribution to the $\mathrm{m} / \mathrm{z}$ peak ( $63 \%$ compared with $26 \%$ from pinonic acid). An isomer of this hydroxyl pinonaldehyde has previously been identified by Yu et al. $(1998,1999)$ during $\alpha$ pinene ozonolysis. The mass channel $\mathrm{m} / \mathrm{z} 153$ is explained in the simulation by the dehydrated form of protonated species (having an $\mathrm{RH}^{+} \mathrm{m} / \mathrm{z}$ of 171), such as 2,3-pinanediol or pinalic-3-acid. Yu et al. (2008) have assigned $\mathrm{m} / z 153$ to the protonated form, $\mathrm{RH}^{+}$, of pinene oxide. Pinene oxide is a first oxidation product of $\alpha$-pinene ozonolysis formed with a yield of 3\% (Berndt et al., 2003). The formation of pinene oxide is not included in the MCMv3.1, but could in reality contribute to the observed $\mathrm{m} / \mathrm{z}, 153$ peak. However, the contribution of pinene oxide to the $\mathrm{m} / \mathrm{z} 153$ peak is expected to be low due to its extensive fragmentation in the CIR-TOF-MS (see Table 3). The observed peaks at $\mathrm{m} / \mathrm{z}, 149$ and $m / z, 165$ are absent in the simulated spectrum. Neither of these peaks correspond to first generation products formed by the alternative $\mathrm{OH}$-initiated oxidation pathways of $\alpha$-pinene identified by Peeters et al. (2001), Fantechi et al. (2002), Vereecken and Peeters (2004) or Vereecken et al. (2007). Yu et al. (2008) have assigned the peak at $\mathrm{m} / \mathrm{z} 165$ to be the dehydrated fragment ion of 4-oxo-pinonaldehyde. The simulated $\mathrm{RH}^{+}$peak at $\mathrm{m} / z, 159$ is absent in the CIR-TOFMS data but could correspond to a dehydrated fragment at $m / z$ 141. The MCM names of the species contributing to the simulated $\mathrm{m} / \mathrm{z}, 159$ are $\mathrm{C} 811 \mathrm{OH}, \mathrm{C} 89 \mathrm{OOH}$ and $\mathrm{C} 717 \mathrm{OH}$. A number of simulated SVOC species of interest $(\mathrm{m} / z, 201,189$, 187,175 ) have not been detected by the CIR-TOF-MS either as a protonated parent ion or as a dehydrated fragment ion. However, species having a similar molar mass were found in the condensed phase (see Sect. 5.2). These species were possibly not detected by CIR-TOF-MS because: (i) they contribute mainly to the composition of the condensed phase, with gaseous concentrations under the CIR-TOF-MS detection limit (simulated concentrations were between 10 and $50 \mathrm{ppt}$ ) or (ii) they have very low vapour pressures and hence could condense onto the walls of the CIR-TOF-MS inlet line, although it is also possible that the mechanism is incorrect and theses species are not in fact formed in the $\alpha$-pinene oxidation system.

\subsection{Condensed phase organic speciation}

\subsubsection{The observed ESI-MS mass spectrum}

The mass spectral distribution of condensed organics was measured by ESI-MS. A detailed description of the instrument is given by Hamilton et al. (2008). As for the CIR-TOFMS only details required to interpret the ESI-MS $m / z$ spectra are briefly presented. The aerosol filter sampled at the conclusion of the experiment was extracted by sonication using water as a solvent (e.g. Hamilton et al., 2008). The extracted solution was directly infused into the electrospray ionisation source using a syringe pump and analysed using an ion trap mass spectrometer to obtain a mass distribution. Electrospray ionisation is a soft ionisation method expected to result in minimal fragmentation. The mass spectrometer was used both in positive and negative ionization modes. In positive ionisation, ions are produced by protonation or cationisation with sodium ions $\left(\mathrm{Na}^{+}\right)$. The sodium ion adducts of the analyte $\mathrm{R},[\mathrm{R}+\mathrm{Na}]^{+}$dominate, leading to $[\mathrm{M}+23]^{+}$ions for most oxygenated compounds. The sodium (present in the glassware used in the analysis) can in the case of oxygenated functionalities improve detection and sensitivity (Hamilton et al., 2008). Negative ionisation mode leads to formation of deprotonated ions $[\mathrm{M}-\mathrm{H}]^{-}$and gives a response primarily for species bearing an acidic hydrogen. The analyte, $\mathrm{R}$, is thus observed as the $[\mathrm{R}+\mathrm{Na}]^{+}$ion at $\mathrm{m} / z[\mathrm{M}+23]^{+}$in the positive mode and as the $[\mathrm{R}-\mathrm{H}]^{-}$ion at $m / z[\mathrm{M}-1]^{-}$in the negative mode. The ESI-MS mass resolution was around $1 \mathrm{Da}$.

\subsubsection{The simulated condensed phase mass spectrum}

A "simulated condensed phase mass spectrum" has been produced from the modelled SOA composition in the same way as for the gaseous mass spectrum, for comparison with the observed ESI-MS mass spectrum:

1. $\mathrm{m} / \mathrm{z}$ peak for each species $\mathrm{R}$ : ions considered for the positive mode were the $[\mathrm{R}+\mathrm{Na}]^{+}$ adducts giving a $\mathrm{m} / \mathrm{z}[\mathrm{M}+23]^{+}$peak for all species and for the negative mode the $[\mathrm{R}-\mathrm{H}]^{-}$ions giving a $\mathrm{m} / \mathrm{z}[\mathrm{M}-1]^{-}$peak for species bearing an acid functionality (i.e. $\mathrm{CO}(\mathrm{OH})$ or $\mathrm{CO}(\mathrm{OOH})$ );

2. Intensity of the $m / z$ peaks for each species R: the intensity of each $\mathrm{m} / \mathrm{z}$ peak was assumed to be 
proportional to the simulated concentration of the condensed species R;

3. Total $\mathrm{m} / \mathrm{z}$ intensity at a resolution of $1 \mathrm{Da}$ :

the total intensity of each $\mathrm{m} / \mathrm{z}$ peak was calculated by summing the intensities of all of the ions between $\mathrm{m} / \mathrm{z}-0.5$ and $\mathrm{m} / \mathrm{z}+0.5$.

As for the simulated gaseous signal, this approach assumes that the simulated signal intensity is proportional to the concentration, independent of species identity, whereas in practice the ESI-MS response will be dependent on the species' ionisation efficiency. While a quantitative comparison is not possible, a qualitative comparison between the simulated and ESI-MS measured mass distributions may be made.

\subsubsection{Comparisons of the condensed mass spectra}

The ESI-MS measured spectra are shown in Fig. 7 on the upper y-axis for both the positive and negative ionisation modes. In the positive ionisation mode, a region of monomer type compounds (with $[\mathrm{R}+\mathrm{Na}]^{+}$adducts at $\mathrm{m} / z$ between approximately 160 and $280 \mathrm{Da}$ ) is apparent, and a smaller region of oligomers (with $[\mathrm{R}+\mathrm{Na}]^{+}$adducts at $\mathrm{m} / \mathrm{z}$ between approximately 330 and $430 \mathrm{Da}$ ) can be clearly identified. These two regions are also present in the measured negative ionisation mode spectrum. However the signal in the oligomeric region is rather noisy and most of the peaks are probably due to contamination and in-source creation of acidic dimer artefacts (Muller et al., 2009). These are not formed in positive ionisation. The oligomers observed in positive ionisation mode are not artefacts of the instrument (they can be separated using LC). This oligomeric region is likely the result of accretion reactions of two monomers either in the aerosol or the gas-phase. These oligomers are homo or heterodimers (referred to hereafter simply as "dimers"). The positive ESI-MS and CIR-TOFMS mass distributions are compared in Fig. S3 of the Supplementary material: http://www.atmos-chem-phys.net/10/ 2893/2010/acp-10-2893-2010-supplement.pdf. Here again, a direct comparison of the CIR-TOF-MS and ESI-MS mass distributions is not straightforward owing to the presence of numerous fragment ions in the CIR-TOF-MS spectrum. Only a small $\mathrm{m} / \mathrm{z}$ range of the ESI-MS and CIR-TOF-MS spectra show matching peaks, with species having a molar mass between around 140 and $190 \mathrm{~g} \mathrm{~mol}^{-1}$ (such as 146 , $156,168,170,172,182$ or $184 \mathrm{~g} \mathrm{~mol}^{-1}$ ). Some or all the species contributing to these peaks may therefore be present in both the gaseous and condensed phase simultaneously. Other peaks in this mass range are present in the ESI-MS spectrum but not in the CIR-TOF-MS spectrum. It is possible that these peaks correspond to fragments of analytes formed during the ESI-MS analysis. Species having a mass higher than $184 \mathrm{~g} \mathrm{~mol}^{-1}$ are only present in the ESI-MS spectrum. As noted above, these species may not be detected by CIRTOF-MS as they contribute mainly to the composition of the
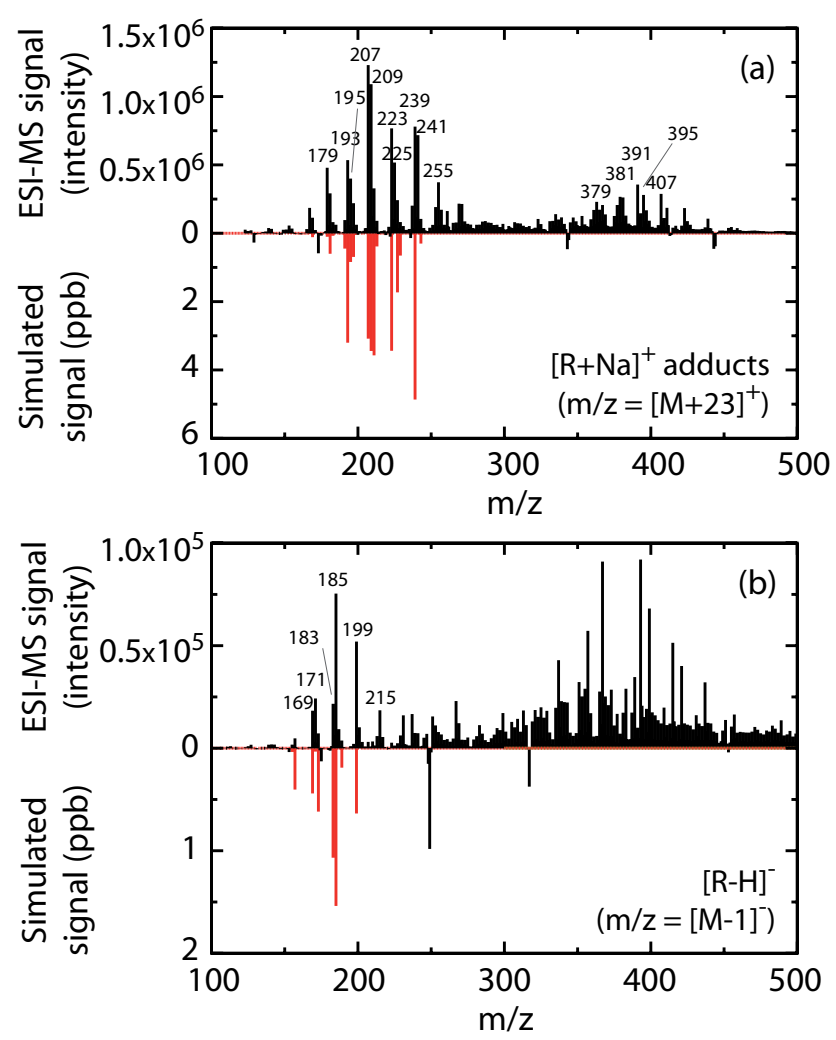

Fig. 7. Condensed phase mass spectra of the $\alpha$-pinene+O $\mathrm{O}_{3}$ EUPHORE experiment using the mass spectrometer in (a) positive ionisation mode and (b) negative ionisation mode. The ESI-MS mass spectrum of the filter taken after the experiment is represented in black on the positive y-axis. The simulated condensed mass spectrum at the end of the experiment is shown in red on the negative $y$-axis. Labels show the $m / z$ value of the more intense peaks.

condensed phase, or alternatively may not be observed due to inlet line losses.

The simulated condensed phase mass spectra are compared with the ESI-MS measured spectra in Fig. 7 on the lower y-axis for both the positive and negative ionisation modes. The observed and simulated peaks in the monomer region are in reasonable agreement for both the positive and negative ionisation spectra. The good correspondence for the positive ionisation indicates that the mass distribution of the products is well simulated, while the agreement for negative mode gives confidence in the assignment of acidic functionality. Therefore, the formation of the majority of the observed condensed phase monomer species can be explained by gas/particle partitioning of the SVOC formed during gas-phase oxidation. All of the peaks present in the simulated mass spectra were observed by the ESI-MS. A few species detected by the ESI-MS in the monomer region (such as $[\mathrm{R}+\mathrm{Na}]^{+}$adducts at $\mathrm{m} / \mathrm{z}, 225$ or 241 and a small section between 240 and $280 \mathrm{Da}$ ) were not present in the simulation. Gaseous compounds with a similar molar mass were 
not detected by the CIR-TOF-MS. The mass distribution in the dimer region is not simulated as no accretion reactions were implemented within the model (see Sect. 5.3).

Structures for the condensed monomer species have been assigned to the major peaks detected by the ESI-MS in the positive and negative ionisation modes on the basis of the simulated speciation. The proposed species with their simulated contribution to the total concentration of condensed species at the same molar mass $\left( \pm 0.5 \mathrm{~g} \mathrm{~mol}^{-1}\right)$ are shown in Table 5. Aerosol extracts were also separated using LC and subjected to Collision Induced Dissociation (CID) to obtain fragmentation patterns, which were used to predict chemical structures of the SOA components. Simulated SOA components that can be identified in the collected aerosol, based on fragmentation patterns, are given in Table 5. Organic acids such as pinonic acid $\left([\mathrm{R}+\mathrm{Na}]^{+}\right.$adduct at $\mathrm{m} / z 207$ and $[\mathrm{R}-\mathrm{H}]^{-}$at $\left.\mathrm{m} / z, 183\right)$, pinic acid $\left([\mathrm{R}+\mathrm{Na}]^{+}\right.$adduct at $\mathrm{m} / \mathrm{z}, 209$ and $[\mathrm{R}-\mathrm{H}]^{-}$at $\mathrm{m} / \mathrm{z}$ 185) or 10-hydroxypinonic acid $\left([\mathrm{R}+\mathrm{Na}]^{+}\right.$adduct at $\mathrm{m} / \mathrm{z}, 223$ and $[\mathrm{R}-\mathrm{H}]^{-}$at $\mathrm{m} / \mathrm{z}$ 199) are simulated to be present in the condensed phase, in agreement with the LC-MS ${ }^{\mathrm{n}}$ analysis and previous studies on SOA formation from $\alpha$-pinene oxidation (e.g. Christoffersen et al., 1998; Hoffmann et al., 1998; Yu et al., 1999; Jang and Kamens, 1999; Glasius et al., 2000; Koch et al., 2000; Iinuma et al., 2004; Jaoui et al., 2005). The $[\mathrm{R}+\mathrm{Na}]^{+}$adduct of pinonic acid at $\mathrm{m} / z, 207$ has the highest observed peak intensity of the positive mode. However a hydroxypinonaldehyde is simulated to contribute $54 \%$ to the total concentration of the $[\mathrm{R}+\mathrm{Na}]^{+}$adduct at $m / z 207$ and pinonic acid $35 \%$. An isomer of hydroxypinonaldehyde has previously been identified in the condensed phase by Yu et al. (1999). Norpinic acid was also detected here within the condensed phase by LC-MS ${ }^{\mathrm{n}}$ and has also been observed in previous studies (e.g. Kavouras et al., 1998; Glasius et al., 2000; Iinuma et al., 2004). In this study the concentration of norpinic acid is simulated to be very low, in both the condensed and gaseous phases. The simulated $[\mathrm{R}+\mathrm{Na}]^{+}$adduct at $\mathrm{m} / \mathrm{z}, 195$ in the positive mode (which would correspond to norpinic acid) is explained by a dihydroxyaldehyde species, and the corresponding simulated $[\mathrm{R}-\mathrm{H}]^{-}$peak intensity at $\mathrm{m} / \mathrm{z} 171$ in the negative mode is very low in comparison to that observed. The formation of norpinic acid from gaseous oxidation could be underestimated in the MCMv3.1. However, the large contribution of norpinic acid to SOA formation from $\alpha$-pinene ozonolysis has been questioned by Claeys et al. (2009) who have instead assigned a terpenylic acid to the norpinic mass channel. This terpenylic acid is suggested to be formed during the OH-initiated $\alpha$-pinene oxidation after intramolecular isomerisation, neither pathways are taken into account in the MCMv3.1. In addition to these di- or multifunctional carboxylic acids, multifunctional species bearing a hydroperoxide moiety (such as $[\mathrm{R}+\mathrm{Na}]^{+}$adducts at $\mathrm{m} / \mathrm{z}, 209,223$ or 239) are simulated to be significant contributors, in agreement with recent studies (e.g. Docherty et al., 2005; Venkatachari and Hopke, 2008; Reinnig et al., 2009). An isomer of the peroxypinonaldehyde simulated at the $[\mathrm{R}+\mathrm{Na}]^{+}$adduct of $m / 2,223$ has previously been assigned to this mass channel by Reinning et al. (2008). However, few condensed multifunctional species bearing a hydroperoxide moiety have been characterized to date owing to difficulties in their accurate detection and quantification.

Peeters et al. (2001) and Vereecken et al. (2007) have identified alternative OH-initiated oxidation pathways of $\alpha$ pinene, such as isomerisation of the peroxy radical $\mathrm{PR}_{\mathrm{OH}} 3$ (see Fig. 2) by 1,6- $\mathrm{H}$ shift or ring closure, and of the alkoxy radical $\mathrm{AR}_{\mathrm{OH}} 3$ by $1,5-\mathrm{H}$ shift or ring closure. These pathways would lead to the formation of multi-oxygenated secondary species, i.e. further products with low volatily. Such pathways could have a significant impact on the simulated condensed phase mass distribution if implemented in the model. First generation products formed according to these (non-MCM) oxidation pathways are listed in Table 6. All of the species listed have a molar mass that corresponds to a peak present in the positive ESI-MS mass spectrum. The species with molar masses of 184,186 or $200 \mathrm{~g} \mathrm{~mol}^{-1}$ would contribute to the peaks at the $[\mathrm{R}+\mathrm{Na}]^{+}$ adduct of $\mathrm{m} / \mathrm{z}$ 207, 209 and 223 respectively, which correspond to (and hence would be in addition to) species already present in the simulation. The species with molar masses of 202 and $218 \mathrm{~g} \mathrm{~mol}^{-1}$ could account for the unsimulated, but observed, major ESI-MS peaks in the positive spectrum at the $[\mathrm{R}+\mathrm{Na}]^{+}$adducts of $\mathrm{m} / \mathrm{z} 225$ and $\mathrm{m} / \mathrm{z}$ 241. Neither the MCMv3.1 degradation mechanism nor these alternative first generation pathways can account for the observed peaks between 240 and $280 \mathrm{Da}$. We speculate that compounds contributing to these higher masses could be the result of species formed from further (gaseous or condensed phase) oxidation of products not explicitly included in the MCM.

\subsection{Condensed phase oligomers}

\subsubsection{Reactivity in the condensed phase}

As noted, the high molecular weight species detected by ESIMS are probably homo or heterodimeric species. Among the reactions suggested to explain the formation of high molecular weight compounds in SOA, these dimers could result from the reaction of a pair of condensed monomers (e.g. Kroll and Seinfeld, 2008; Hallquist et al., 2009). The simulated speciation of the condensed monomers was used to explore the possible mass distribution of condensed dimers which would form according to various possible accretion reactions for comparison with the observed ESI-MS signal. The accretion reactions investigated were peroxyhemiacetal formation (e.g. Tobias et al., 2000; Tobias and Ziemann, 2000), hemiacetal formation (e.g. Jang and Kamens, 2001; Jang et al., 2002; Garland et al., 2006; Surratt et al., 2006), aldol condensation (e.g. Noziere and Riemer, 2003; Esteve and Noziere, 2005; Garland et al., 2006; Surratt et al., 2006; Casale et al., 2007) and acid anhydride and ester formation 
Table 5. Proposed structures (based on the simulation) for the major monomer compounds detected by the ESI-MS in the positive and negative ionisation modes for the $\alpha$-pinene+ $\mathrm{O}_{3}$ EUPHORE experiment together with their simulated contribution to the total concentration of condensed species having a same molar mass (within $\pm 0.5 \mathrm{~g} \mathrm{~mol}^{-1}$ ). ${ }^{\text {a }}$ Structure confirmed using LC-MS ${ }^{\mathrm{n}}$. ${ }^{\mathrm{b}}$ Isomer of a structure confirmed using LC-MS ${ }^{\mathrm{n}}$ (with two carbons on the acid side rather than the aldehyde side).

\begin{tabular}{|c|c|c|c|c|c|}
\hline$m / \mathbf{z}$ & $\begin{array}{c}\text { Molar mass } \\
\left(\mathrm{g} \mathrm{mol}^{-1}\right)\end{array}$ & Name/Molecular formula & Structure & MCM name & $\begin{array}{c}\text { Simulated } \\
\text { contribution }\end{array}$ \\
\hline$[\mathrm{R}+\mathrm{Na}]^{+}$ & \multicolumn{5}{|c|}{ Positive ionisation mode } \\
\hline \multirow[t]{2}{*}{207} & 184.23 & $\mathrm{C}_{10} \mathrm{H}_{16} \mathrm{O}_{3}$ & & $\mathrm{C} 107 \mathrm{OH}$ & $54 \%$ \\
\hline & 184.23 & pinonic acid $^{\mathrm{a}}$ & & PINONIC & $35 \%$ \\
\hline \multirow[t]{3}{*}{209} & 186.21 & $\operatorname{pinic}_{\text {acid }^{a}}$ & & PINIC & $44 \%$ \\
\hline & 186.25 & $\mathrm{C}_{10} \mathrm{H}_{18} \mathrm{O}_{3}$ & & APINAOOH & $31 \%$ \\
\hline & 186.25 & $\mathrm{C}_{10} \mathrm{H}_{18} \mathrm{O}_{3}$ & & APINCOOH & $23 \%$ \\
\hline 239 & 216.23 & $\mathrm{C}_{10} \mathrm{H}_{16} \mathrm{O}_{5}$ & & $\mathrm{C} 108 \mathrm{OOH}$ & $97 \%$ \\
\hline \multirow[t]{3}{*}{223} & 200.23 & $\mathrm{C}_{10} \mathrm{H}_{16} \mathrm{O}_{4}$ & & $\mathrm{C} 108 \mathrm{OH}$ & $36 \%$ \\
\hline & 200.23 & $\mathrm{C}_{10} \mathrm{H}_{16} \mathrm{O}_{4}$ & & $\mathrm{C} 107 \mathrm{OOH}$ & $30 \%$ \\
\hline & 200.23 & 10-hydroxypinonic acid ${ }^{\mathrm{a}}$ & & HOPINONIC & $19 \%$ \\
\hline 241 & & Absent in the simulation & & & \\
\hline \multirow[t]{2}{*}{193} & 170.25 & 2,3-pinanediol & & APINBOH & $82 \%$ \\
\hline & 170.21 & $\mathrm{C}_{9} \mathrm{H}_{14} \mathrm{O}_{3}{ }^{\mathrm{b}}$ & & $\mathrm{C} 89 \mathrm{CO} 2 \mathrm{H}$ & $14 \%$ \\
\hline 225 & & Absent in the simulation & & & \\
\hline \multirow[t]{3}{*}{179} & 156.18 & $\mathrm{C}_{8} \mathrm{H}_{12} \mathrm{O}_{3}{ }^{\mathrm{a}}$ & & $\mathrm{C} 721 \mathrm{CHO}$ & $35 \%$ \\
\hline & 156.14 & $\mathrm{C}_{7} \mathrm{H}_{8} \mathrm{O}_{4}$ & & $\mathrm{CO} 235 \mathrm{C} 6 \mathrm{CHO}$ & $33 \%$ \\
\hline & 156.22 & $\mathrm{C}_{9} \mathrm{H}_{16} \mathrm{O}_{2}{ }^{\mathrm{a}}$ & & $\mathrm{C} 96 \mathrm{OH}$ & $32 \%$ \\
\hline \multirow[t]{2}{*}{195} & 172.22 & $\mathrm{C}_{9} \mathrm{H}_{16} \mathrm{O}_{3}$ & & $\mathrm{C} 97 \mathrm{OH}$ & $96 \%$ \\
\hline & 172.18 & norpinic acid ${ }^{\mathrm{a}}$ & & NORPINIC & $<5 \%$ \\
\hline 255 & \multirow{2}{*}{\multicolumn{5}{|c|}{$\begin{array}{l}\text { Absent in the simulation } \\
\text { Negative ionisation mode (acids) }\end{array}$}} \\
\hline$[\mathrm{R}-\mathrm{H}]^{-}$ & & & & & \\
\hline 185 & 186.21 & pinic acid $^{\text {a }}$ & & PINIC & $100 \%$ \\
\hline 199 & 200.23 & 10-hydroxypinonic acid ${ }^{\mathrm{a}}$ & & HOPINONIC & $100 \%$ \\
\hline 171 & 172.18 & norpinic acid ${ }^{a}$ & & NORPINIC & $100 \%$ \\
\hline 183 & 184.23 & pinonic acid $^{\mathrm{a}}$ & & PINONIC & $100 \%$ \\
\hline 169 & 170.21 & $\mathrm{C}_{9} \mathrm{H}_{14} \mathrm{O}_{3}{ }^{\mathrm{a}}$ & & $\mathrm{C} 89 \mathrm{CO} 2 \mathrm{H}$ & $100 \%$ \\
\hline 215 & & Absent in the simulation & & & \\
\hline
\end{tabular}

(e.g. Gao et al., 2004; Hamilton et al., 2006; Muller et al., 2008). These potential reactions are shown schematically in Fig. 8. Combination reactions occurring in the gaseous phase followed by gas-particle partitioning, such as peroxy radical self reactions (e.g. Ziemann, 2002) and stabilized Criegee reactions with other oxygenates (Sadezky et al., 2006; Heaton et al., 2007; Zahardis and Petrucci, 2007), could also represent a significant pathway for formation of the observed dimers (e.g. Muller et al., 2009) but are not considered here. 
Peroxyhemiacetal formation

$\mathrm{R}_{1} \bigvee_{\mathrm{O}}+\mathrm{R}_{2}-\mathrm{OOH}$

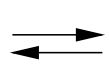

$\overbrace{\mathrm{R}_{1}}^{\mathrm{OH}} \overbrace{\mathrm{R}_{2}}$

Hemiacetal formation

$$
\stackrel{\mathrm{R}_{1}}{=\mathrm{O}}+\mathrm{R}_{2}-\mathrm{OH} \rightleftharpoons \mathrm{R}_{1} \overbrace{\mathrm{O}^{-R_{2}}}^{\mathrm{OH}}
$$

Aldol condensation
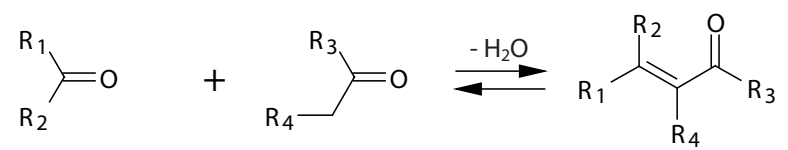

Ester formation<smiles>[R]C(=O)O</smiles>
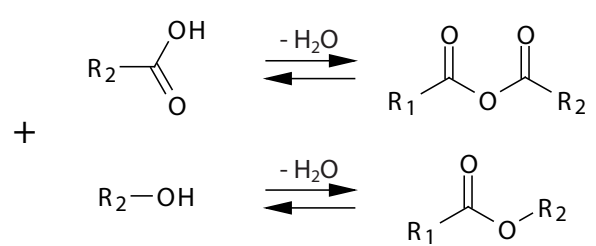

Fig. 8. Mechanisms for potential accretion reactions between two condensed phase monomers investigated here.

\subsubsection{The simulated condensed phase mass spectrum for dimers}

For a given accretion reaction involving a pair of condensed monomers bearing functionalities $i$ and $j$, each simulated monomer A having a function $i$ was combined with each simulated monomer $\mathrm{B}$ having a function $j$. The mass of the dimer species formed $\mathrm{AB}$ (or $\mathrm{AB}-\mathrm{H}_{2} \mathrm{O}$ if dehydration occurs) was $M=M_{\mathrm{A}}+M_{\mathrm{B}}$, where $M_{\mathrm{A}}$ is the molar masses of the monomers A (or potentially $M_{\mathrm{A}}+M_{\mathrm{B}}-18$ if dehydration occurs). For each investigated accretion reaction a "simulated condensed phase mass spectrum" of the species AB was produced for comparison with the observed positive ionisation mode ESI-MS mass spectrum where:

1. $m / z$ peak for each dimer $\mathrm{R}$ :

ions considered were the $[\mathrm{R}+\mathrm{Na}]^{+}$adducts giving a $\mathrm{m} / \mathrm{z}$ $[\mathrm{M}+23]^{+}$peak for each dimer;

2. Intensity of the $m / z$ peaks for each dimer R: the intensity of each $\mathrm{m} / z$ peak was proportional to $n f_{i \mathrm{~A}} \times n f_{j \mathrm{~B}} \times C_{\mathrm{A}} \times C_{\mathrm{B}}$, where $n f_{i \mathrm{~A}}$ is the number of occurrences of functional group $i$ within monomer $\mathrm{A}$, and $C_{\mathrm{A}}$ the simulated concentration of the monomer $\mathrm{A}$ in the condensed phase, by analogy with the production rate $d C_{\mathrm{AB}} / d t$

3. Total $\mathrm{m} / \mathrm{z}$ intensity at a resolution of $1 \mathrm{Da}$ :

the total intensity of each integer $\mathrm{m} / \mathrm{z}$ peak was calculated by summing the intensities of all the peaks between $m / z-0.5$ and $m / z+0.5$.

Comparison of the simulated condensed phase spectrum for dimers with the observed ESI-MS spectrum is exploratory

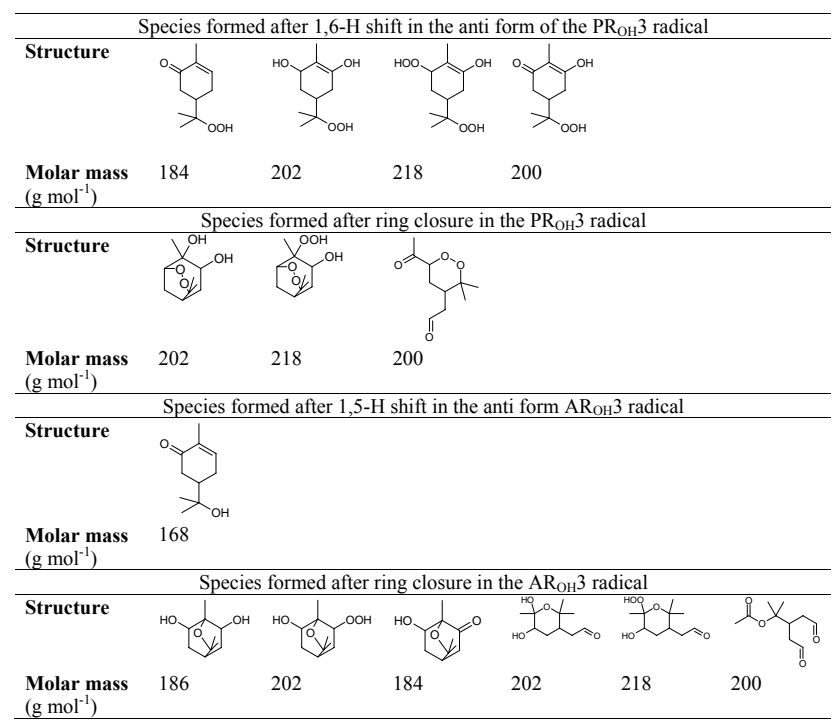

Table 6. First generation products formed by the alternative $\mathrm{OH}-$ initiated oxidation pathways of $\alpha$-pinene identified by Peeters et al. (2001) and Vereecken et al. (2007).

considering that this approach is necessarily directly linked to the simulated composition of SVOC monomers present in the condensed phase.

\subsubsection{Comparisons of the condensed dimer mass spectra}

The simulated condensed-phase dimer mass spectra for those accretion reactions considered are compared with the observed mass spectrum under positive ionisation mode in Fig. 9. Many of the observed features in the dimer region of the measured spectrum $\left([\mathrm{R}+\mathrm{Na}]^{+}\right.$adducts at $\mathrm{m} / \mathrm{z}$ between 300 and 500) are consistent with all of the accretion reactions considered, however peroxyhemiacetal and hemiacetal formation reactions fail to represent dimers with the lowest masses $\left([\mathrm{R}+\mathrm{Na}]^{+}\right.$adducts at $\left.m / z<360\right)$ and lead to dimers with higher masses than those observed $\left([\mathrm{R}+\mathrm{Na}]^{+}\right.$adducts at $m / z>440$ ) (Fig. 9a and b). Hemiacetal formation has previously been found to be thermodynamically unfavourable (Barsanti et al., 2004). Accretion reactions involving dehydration, such as aldol condensation and esterification, result in a better agreement between the simulated and observed dimer mass spectra (Fig. 9c and d). Dehydration has already been observed to take place during dimer formation in SOA from terpene ozonolysis (Reinhardt et al., 2007; Walser et al., 2008; Muller et al., 2009). Aldol condensation in isolation does not explain the formation of all the observed masses, with around one third of observed peaks missing (Fig. 9c). Aldol condensation has been found to be favourable thermodynamically (Barsanti et al., 2004) but may be acid catalysed (e.g. Kroll et al., 2008), probably not representative of our experimental conditions. Esterification reactions result 
in a modelled dimer mass distribution in very good agreement with the observed ESI-MS spectrum (Fig. 9d), although most of the highest masses $\left([\mathrm{R}+\mathrm{Na}]^{+}\right.$adducts at $\left.\mathrm{m} / z>400\right)$ are not present in the simulated dimer spectrum. This correlates with the lack of the simulated masses in the monomer region observed by the ESI-MS for $[\mathrm{R}+\mathrm{Na}]^{+}$adducts at $\mathrm{m} / \mathrm{z}$ between 240 and 270, resulting in a subsequent lack of dimer masses of $[\mathrm{R}+\mathrm{Na}]^{+}$adducts at $m / z$ around 400 and 460 . Esterification reactions are thermodynamically viable (Barsanti et al., 2006).

Figure 10 shows examples of the simulated dimer structures for the $m / z$ peak with the highest intensity observed by ESI-MS (i.e. $[\mathrm{R}+\mathrm{Na}]^{+}$adduct at $\mathrm{m} / z$ 391, $\mathrm{M}=368 \mathrm{~g} \mathrm{~mol}^{-1}$ ). Muller et al. (2009) have chemically analysed the structure of species having this molar mass. A dimeric species formed by esterification and highlighted in red in Fig. 10 is in agreement with the chemical analysis. Each accretion reaction has been investigated independently here whereas in practice these reactions could very well occur in parallel in the condensed phase. The qualitative agreement apparent in Fig. 9d leads us to infer that esterification reactions between the condensed monomers may be the dominant processes forming dimeric species during $\alpha$-pinene ozonolysis experiment. We note however that the various dimeric species will differ in stability. Peroxyhemiacetals are likely to be thermally labile and unstable compounds (Jang et al., 2002; Surratt et al., 2006). During ESI, samples are subjected to temperatures of up to $350^{\circ} \mathrm{C}$ within the ion source. Any thermally labile groups may therefore fragment during analysis. For example, we have found that many peroxide standards probed using this technique fragment by loss of water within the source and are effectively unobservable. Such fragmentation may also potentially convert dimers back to monomers, or indeed to different monomers. This may account for some of the low molecular weight peaks that cannot be explained using known reaction mechanisms noted in Sect. 5.2.3. In addition, neutral oligomers (including some peroxyhemiacetals) are not ionisable using the ESI source. Esters would then be the main species observed by ESI-MS due to their stability and ionisation efficiency.

\section{Conclusions}

SOA formation from dark $\alpha$-pinene ozonolysis has been studied with an emphasis upon the composition of gaseous and condensed phase SVOC, interpreted qualitatively in terms of their measured and simulated mass distributions. In the course of EUPHORE chamber simulations, the gas-phase oxygenated organic product evolution and distribution was followed using an online CIR-TOF-MS. The semi-volatile oxygenated organic distribution in the condensed phase was acquired through off-line ESI-MS analysis of SOA filters taken at the end of the experiment. A detailed chamber box model designed to simulate SOA formation has been

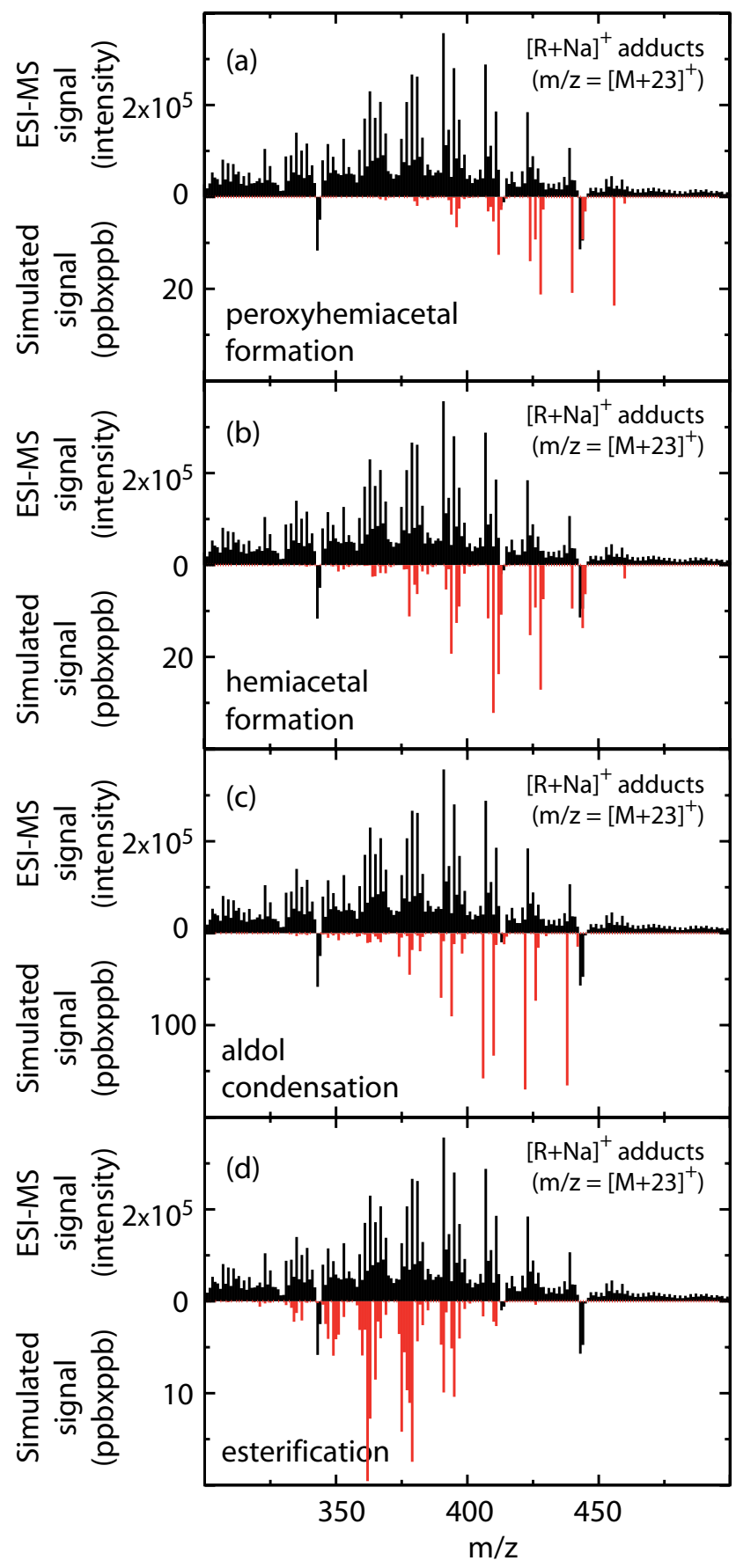

Fig. 9. Condensed-phase dimer mass spectra under positive ionisation mode for the $\alpha$-pinene $+\mathrm{O}_{3}$ EUPHORE experiment. The observed ESI-MS mass spectrum is shown on the positive y-axis in each box, while that simulated for different accretion reactions is shown in red in the negative y-axis region. The panels show in isolation (a) peroxyhemiacetal formation, (b) hemiacetal formation, (c) aldol condensation and (d) esterification. 

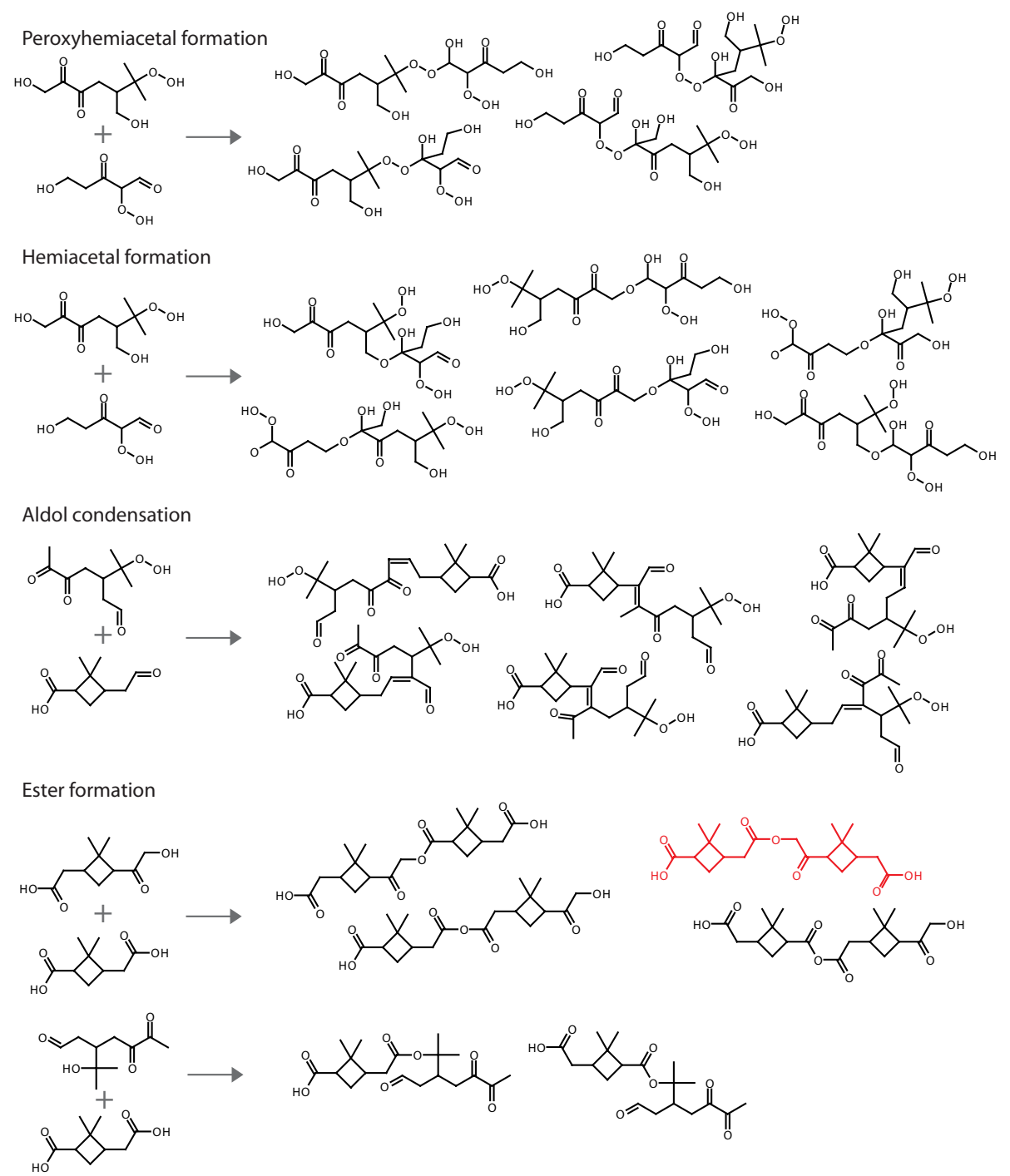

Fig. 10. Example of structures for dimer species formed from accretion reactions of the simulated monomers for the major peak detected by the ESI-MS (i.e. $[\mathrm{R}+\mathrm{Na}]^{+}$adduct at $\mathrm{m} / z, 391, \mathrm{M}=368 \mathrm{~g} \mathrm{~mol}^{-1}$ ). The chemical structure in agreement with the chemical analysis of Muller et al. (2009) is highlighted in red.

developed for comparison with the experimental results, coupling an equilibrium gas/particle partitioning module to the $\alpha$-pinene oxidation scheme extracted from the MCMv3.1.

The simulated temporal profile of SOA mass for these specific $\alpha$-pinene ozonolysis experiments is in reasonable agreement with the observations, both in terms of the shape and magnitude, when vapour pressures of SVOC are calculated using the Myrdal and Yalkowsky method with Joback boiling point estimates. A sensitivity analysis showed that the large differences in published model performances with respect to the simulation of the temporal evolution of SOA mass formation from $\alpha$-pinene ozonolysis may be largely a consequence of the use of different methods for SVOC vapour pressure estimation. Reduction in the uncertainties associated with vapour pressure estimates is crucial for the development of reliable organic gas/particle partitioning; however the evaluation of vapour pressure estimation methods for the purpose of SOA modelling is still limited by the availability of experimental data for organic species of interest, i.e. oxygenated species bearing hydroperoxide or nitrate moieties and multifunctional species having vapour pressures lower than $10^{-6}$ atm.

Recent results however suggest that the Myrdal and Yalkowsky approach coupled with Joback may systematically underestimates vapour pressures, and indicate that alternative approaches such as the Nannoolal methods are more accurate. Their adoption leads to vapour pressures lowered by one to two orders of magnitude, and results in a significant model underestimate of the observed SOA mass. This underestimate may then be compensated for by 
omission of pathways forming SVOC from the MCM chemical scheme for $\alpha$-pinene oxidation, and/or by reactions in the condensed phase forming larger species with lower volatility. Some evidence for the occurrence of recently suggested peroxy-radical isomerisation channels is found in the mass spectral data. A sensitivity study into the dependence of the simulated SOA mass upon the timescale of oligomerisation indicated that, other uncertainties notwithstanding, a lifetime for SVOC in the condensed phase of the order of 5 min was required to bring the simulated SOA mass into agreement with the observed levels. Time-resolved measurements of SOA composition are needed to give constraints on the timescales of condensed phase reactivity.

Comparisons of the simulated mass spectrum with the CIR-TOF-MS mass spectrum show a similar mass distribution for gaseous organics. The simulated composition for the major peaks detected by the CIR-TOF-MS is in agreement with previous identifications of products formed during $\alpha$-pinene ozonolysis. Identification of the main peaks of gaseous SVOC present in the CIR-TOF-MS spectrum has been proposed on the basis of the simulated composition. The ESI-MS measurements show the presence in the condensed phase of monomer and oligomer type organics. Comparisons of the simulated condensed phase mass spectrum with the ESI-MS mass spectrum show that most of the peaks in the monomer region are in reasonable agreement, i.e. explained in the simulation by the gas/particle partitioning of SVOC formed during the gas-phase oxidation of $\alpha$ pinene. A chemical structure for the principal condensedphase monomers detected has been proposed on the basis of the simulated composition and known LC-MS fragmentation patterns.

Oligomer species detected by the ESI-MS are likely to be the result of accretion reactions occurring in the condensed phase and/or in the gaseous phase. The possible influence of a range of accretion reactions occurring in the condensed phase on the mass distribution of condensed dimers has been explored independently, drawing upon the simulated composition of the condensed monomers. Accretion reactions investigated were: peroxyhemiacetal formation, hemiacetal formation, aldol condensation and esterification. Comparisons of the simulated mass distribution of dimers with the observed mass spectrum suggest that esterification reactions are the dominant process involved in this system. This approach offers a route to identifying the SVOC leading to SOA formation by gas/particle partitioning, which may in turn allow their chemical ageing to be simulated on timescales which are experimentally inaccessible. Extending this approach to characterising the gaseous and particulate organic composition from other organic precursors and under various experimental conditions will help correctly understand SOA formation, and therefore assist in the development of reliable SOA schemes in 3-D chemical transport models.
Acknowledgements. The authors wish to gratefully acknowledge Chris Martin for providing the box model and useful discussions with regards to the coupling of the kinetic and partitioning modules, and Mike Jenkin and Gordon McFiggans for in depth discussions and helpful comments. The authors also thank co-workers from CEAM for technical support during the TRAPOZ experiments performed at EUPHORE. The TRAPOZ project was funded by the Natural Environment Research Council (Grant Ref NE/E016081/1). Offline aerosol analysis was funded by the NERC APPRAISE Core Post (Grand Ref R8/H10/34).

Edited by: G. McFiggans

\section{References}

Asher, W. E., Pankow, J. F., Erdakos, G. B., and Seinfeld, J. H.: Estimating the vapor pressures of multifunctional oxygencontaining organic compounds using group contribution methods, Atmos. Environ., 36, 1483-1498, 2002.

Asher, W. E. and Pankow, J. F.: Vapor pressure prediction for alkenoic and aromatic organic compounds by a UNIFAC-based group contribution method, Atmos. Environ., 40, 3588-3600, 2006.

Aumont, B., Szopa, S., and Madronich, S.: Modelling the evolution of organic carbon during its gas-phase tropospheric oxidation: development of an explicit model based on a self generating approach, Atmos. Chem. Phys., 5, 2497-2517, 2005, http://www.atmos-chem-phys.net/5/2497/2005/.

Barley, M. H. and McFiggans, G.: The critical assessment of vapour pressure estimation methods for use in modelling the formation of atmospheric organic aerosol, Atmos. Chem. Phys., 10, 749767, 2010,

http://www.atmos-chem-phys.net/10/749/2010/.

Barsanti, K. C. and Pankow, J. F.: Thermodynamics of the formation of atmospheric organic particulate matter by accretion reactions - Part 1: aldehydes and ketones, Atmos. Environ., 38, 4371-4382, 2004.

Barsanti, K. C. and Pankow, J. F.: Thermodynamics of the formation of atmospheric organic particulate matter by accretion reactions - Part 3: Carboxylic and dicarboxylic acids, Atmos. Environ., 40, 6676-6686, 2006.

Becker, K. H.: The European Photoreactor EUPHORE, Final Report to the European Commission, Contract \#EV5V-CT92-0059, Bergische Universität Wuppertal, Germany, 1996.

Becker, K. H.: In situ Euphore Radical Measurement (EUPHORAM): Final Report to the European Commission, Contract \#ENV4-CT95-0011, Bergische Universität Wuppertal, Germany, 1999.

Berndt, T., Böge, O., and Stratmann, F.: Gas-phase ozonolysis of $\alpha$-pinene: gaseous products and particle formation, Atmos. Environ., 37, 3933-3945, 2003.

Blake, R. S., Whyte, C., Hughes, C. O., Ellis, A. M., and Monks, P. S.: Demonstration of Proton-Transfer Reaction Time-of-Flight Mass Spectrometry for real-time analysis of trace volatile organic compounds, Anal. Chem., 76, 3841-3845, 2004.

Blake, R. S., Wyche, K. P., Ellis, A. M., and Monks, P. S.: Chemical ionization reaction time-of-flight mass spectrometry: Multireagent analysis for determination of trace gas composition, Int. J. Mass Spectrom., 254, 85-93, 2006. 
Blake, R. S., Monks, P. S., and Ellis, A. M.: Proton-Transfer Reaction Mass Spectrometry, Chem. Rev., 109, 861-896, 2009.

Bloss, W. J., Lee, J. D., Bloss, C., Heard, D. E., Pilling, M. J., Wirtz, K., Martin-Reviejo, M., and Siese, M.: Validation of the calibration of a laser-induced fluorescence instrument for the measurement of $\mathrm{OH}$ radicals in the atmosphere, Atmos. Chem. Phys., 4, 571-583, 2004,

http://www.atmos-chem-phys.net/4/571/2004/.

Bloss, C., Wagner, V., Jenkin, M. E., Volkamer, R., Bloss, W. J., Lee, J. D., Heard, D. E., Wirtz, K., Martin-Reviejo, M., Rea, G., Wenger, J. C., and Pilling, M. J.: Development of a detailed chemical mechanism (MCMv3.1) for the atmospheric oxidation of aromatic hydrocarbons, Atmos. Chem. Phys., 5, 641664, 2005a,

http://www.atmos-chem-phys.net/5/641/2005/.

Bloss, C., Wagner, V., Bonzanini, A., Jenkin, M. E., Wirtz, K., Martin-Reviejo, M., and Pilling, M. J.: Evaluation of detailed aromatic mechanisms (MCMv3 and MCMv3.1) against environmental chamber data, Atmos. Chem. Phys., 5, 623-639, 2005, http://www.atmos-chem-phys.net/5/623/2005/.

Camredon, M. and Aumont, B.: Assessment of vapor pressure estimation methods for secondary organic aerosol modeling, Atmos. Environ., 40, 2105-2116, 2006.

Camredon, M., Aumont, B., Lee-Taylor, J., and Madronich, S.: The SOA/VOC/NO $\mathrm{X}_{\mathrm{X}}$ system: an explicit model of secondary organic aerosol formation, Atmos. Chem. Phys., 7, 5599-5610, 2007, http://www.atmos-chem-phys.net/7/5599/2007/.

Capouet, M., Müller, J.-F., Ceulemans, K., Compernolle, S., Vereecken, L., and Peeters, J.: Modeling aerosol formation in alpha-pinene photo-oxidation experiments, J. Geophys. Res., 113, D02308, doi:10.1029/2007JD008995, 2008.

Casale, M. T., Richman, A. R., Elrod, M. J., Garland, R. M., Beaver, M. R., and Tolbert, M. A.: Kinetics of acid-catalyzed aldol condensation reactions of aliphatic aldehydes, Atmos. Environ., 41, 6212-6224, 2007.

Claeys, M., Iinuma, Y., Szmigielski, R., Surratt, J. D., Blockhuys, F., Van Alsenoy, C., Boge, O., Sierau, B., Gomez-Gonzalez, Y., Vermeylen, R., Van der Veken, P., Shahgholi, M., Chan, A. W. H., Herrmann, H., Seinfeld, J. H., and Maenhaut, W.: Terpenylic Acid and Related Compounds from the Oxidation of alpha-Pinene: Implications for New Particle Formation and Growth above Forests, Environ. Sci. Technol., 43, 6976-6982, 2009.

Christoffersen, T. S., Hjorth, J., Horie, O., Jensen, N. R., Kotzias, D., Molander, L. L., Neeb, P., Ruppert, L., Winterhalter, R., Virkkula, A., Wirtz, K., and Larsen, B. R.: cis-Pinic acid, a possible precursor for organic aerosol formation from ozonolysis of $\alpha$-pinene, Atmos. Environ., 32, 1657-1661, 1998.

Clegg, S. L., Kleeman, M. J., Griffin, R. J., and Seinfeld, J. H.: Effects of uncertainties in the thermodynamic properties of aerosol components in an air quality model - Part 1: Treatment of inorganic electrolytes and organic compounds in the condensed phase, Atmos. Chem. Phys., 8, 1057-1085, 2008, http://www.atmos-chem-phys.net/8/1057/2008/.

Czoschke, N., Jang, M., and Kamens, R.: Effect of acidic seed on biogenic secondary organic aerosol growth, Atmos. Environ., 37, 4287-4299, 2003.
Docherty, K. S., Wu, W., Lim, Y. B., and Ziemann, P. J.: Contributions of organic peroxides to secondary aerosol formed from reactions of monoterpenes with $\mathrm{O}_{3}$, Environ. Sci. Technol., 39, 4049-4059, 2005.

Esteve, W. and Noziere, B.: Uptake and reaction kinetics of acetone, 2-butanone, 2,4-pentanedione, and acetaldehyde in sulfuric acid solutions, J. Phys. Chem. A, 109, 10920-10928, 2005.

Fantechi, G., Vereecken, L., and Peeters, J.: The OH-initiated atmospheric oxidation of pinonaldehyde: Detailed theoretical study and mechanism construction, Phys. Chem. Chem. Phys., 4, 5795-5805, 2002.

Fuzzi, S., Andreae, M. O., Huebert, B. J., Kulmala, M., Bond, T. C., Boy, M., Doherty, S. J., Guenther, A., Kanakidou, M., Kawamura, K., Kerminen, V.-M., Lohmann, U., Russell, L. M., and Pöschl, U.: Critical assessment of the current state of scientific knowledge, terminology, and research needs concerning the role of organic aerosols in the atmosphere, climate, and global change, Atmos. Chem. Phys., 6, 2017-2038, 2006,

http://www.atmos-chem-phys.net/6/2017/2006/.

Gao, S., Ng, N. L., Keywood, M., Varutbangkul, V., Bahreini, R., Nenes, A., He, J., Yoo, K. Y., Beauchamps, J. L., Hodyss, R. P., Flagan, R., and Seinfeld, J. H.: Particle phase acidity and oligomer formation in secondary organic aerosol, Environ. Sci. Technol., 38, 6582-6589, 2004.

Garland, R. M., Elrod, M. J., Kincaid, K., Beaver, M. R., Jimenez, J. L., and Tolbert, M. A.: Acid-catalyzed reactions of hexanal on sulfuric acid particles: Identification of reaction products, Atmos. Environ., 40, 6863-6878, 2006.

Glasius, M., Lahaniati, M., Calogirou, A., Di Bella, D., Jensen, N. R., Hjorth, J., Kotzias, D., and Larsen, B. R.: Carboxylic Acids in Secondary Aerosols from Oxidation of Cyclic Monoterpenes by Ozone, Environ. Sci. Technol., 34, 1001-1010, 2000.

Goldstein, A. H. and Galbally, I. E.: Known and unexplored organic constituents in the earth's atmosphere, Environ. Sci. Technol., 41, 1514-1521, 2007.

Hallquist, M., Wenger, J. C., Baltensperger, U., Rudich, Y., Simpson, D., Claeys, M., Dommen, J., Donahue, N. M., George, C., Goldstein, A. H., Hamilton, J. F., Herrmann, H., Hoffmann, T., Iinuma, Y., Jang, M., Jenkin, M. E., Jimenez, J. L., Kiendler-Scharr, A., Maenhaut, W., McFiggans, G., Mentel, Th. F., Monod, A., Prévôt, A. S. H., Seinfeld, J. H., Surratt, J. D., Szmigielski, R., and Wildt, J.: The formation, properties and impact of secondary organic aerosol: current and emerging issues, Atmos. Chem. Phys., 9, 5155-5236, 2009, http://www.atmos-chem-phys.net/9/5155/2009/.

Hamilton, J. F., Lewis, A. C., Reynolds, J. C., Carpenter, L. J., and Lubben, A.: Investigating the composition of organic aerosol resulting from cyclohexene ozonolysis: low molecular weight and heterogeneous reaction products, Atmos. Chem. Phys., 6, 49734984, 2006, http://www.atmos-chem-phys.net/6/4973/2006/.

Hamilton, J. F., Lewis, A. C., Carey, T. J., and Wenger, J. C.: Characterization of polar compounds and oligomers in secondary organic aerosol using liquid chromatography coupled to mass spectrometry, Anal. Chem., 80, 474-480, 2008.

Heaton, K. J., Dreyfus, M. A., Wang, S., and Johnston, M. V.: Oligomers in the early stage of biogenic secondary organic aerosol formation and growth, Environ. Sci. Technol., 41, 61296136, 2007. 
Hellen, H., Dommen, J., Metzger, A., Gascho, A., Duplissy, J., Tritscher, T., Prevot, A. S. H., and Baltensperger, U.: Using proton transfer reaction mass spectrometry for online analysis of secondary organic aerosols, Environ. Sci. Technol., 42, 73477353, 2008.

Hildebrandt, L., Donahue, N. M., and Pandis, S. N.: High formation of secondary organic aerosol from the photo-oxidation of toluene, Atmos. Chem. Phys., 9, 2973-2986, 2009, http://www.atmos-chem-phys.net/9/2973/2009/.

Hoffmann, T., Bandur, R., Marggraf, U., and Linscheid, M.: Molecular composition of organic aerosols formed in the alphapinene $/ \mathrm{O}_{3}$ reaction: Implications for new particle formation processes, J. Geophys. Res., 103, 25569-25578, 1998.

Iinuma, Y., Boge, O., Gnauk, T., and Herrmann, H.: Aerosolchamber study of the alpha-pinene $/ \mathrm{O}_{3}$ reaction: influence of particle acidity on aerosol yields and products, Atmos. Environ., 38, 761-773, 2004.

Jang, M. and Kamens, R. M.: Newly characterized products and composition of secondary aerosols from the reaction of alphapinene with ozone, Atmos. Environ., 33, 459-474, 1999.

Jang, M. S. and Kamens, R. M.: Characterization of secondary aerosol from the photooxidation of toluene in the presence of $\mathrm{NO}_{\mathrm{x}}$ and 1-propene, Environ. Sci. Technol., 35, 3626-3639, 2001.

Jang, M., Czoschke, N. M., Lee, S., and Kamens, R. M.: Heterogeneous atmospheric organic aerosol production by inorganic acidcatalyzed particle-phase reactions, Science, 298, 814-817, 2002.

Jaoui, M., Kleindienst, T. E., Lewandowski, M., Offenberg, J. H., and Edney, E.O.: Identification and quantification of aerosol polar oxygenated compounds bearing carboxylic or hydroxyl groups, 2. Organic tracer compounds from monoterpènes, Environ. Sci. Technol., 39, 5661-5673, 2005.

Jenkin, M. E., Saunders, S. M., and Pilling, M. J.: The tropospheric degradation of volatile organic compounds: A protocol for mechanism development, Atmos. Environ., 31, 81-104, 1997.

Jenkin, M. E., Shallcross, D. E., and Harvey, J. N.: Development and application of a possible mechanism for the generation of cis-pinic acid form the ozonolysis of $\alpha$ - and $\beta$-pinene, Atmos. Environ., 34, 2837-2850, 2000.

Jenkin, M. E., Saunders, S. M., Wagner, V., and Pilling, M. J.: Protocol for the development of the Master Chemical Mechanism, MCM v3 (Part B): tropospheric degradation of aromatic volatile organic compounds, Atmos. Chem. Phys., 3, 181-193, 2003, http://www.atmos-chem-phys.net/3/181/2003/.

Jenkin, M. E.: Modelling the formation and composition of secondary organic aerosol from $\alpha$ - and $\beta$-pinene ozonolysis using MCM v3, Atmos. Chem. Phys., 4, 1741-1757, 2004, http://www.atmos-chem-phys.net/4/1741/2004/.

Johnson, D., Jenkin, M. E., Wirtz, K., and Martin-Reviejo, M.: Simulating the formation of secondary organic aerosol from photooxidation of toluene, Environ. Chem., 1, 150-165, 2004.

Johnson, D., Jenkin, M. E., Wirtz, K. and Martin-Reviejo, M.: Simulating the formation of SOA from the photooxidation of aromatic hydrocarbons, Environ. Chem., 2, 35-48, 2005.

Johnson, D. and Marston, G.: The gas-phase ozonolysis of unsaturated volatile organic compounds in the troposphere, Chem. Soc. Rev., 37, 699-716, 2008.
Kalberer, M., Paulsen, D., Sax, M., Steinbacher, M., Dommen, J., Prevot, A. S. H., Fisseha, R., Weingartner, E., Frankevich, V., Zenobi, R., and Baltensperger, U.: Identification of polymers as major components of atmospheric organic aerosols, Science, 303, 1659-1662, 2004.

Kanakidou, M., Seinfeld, J. H., Pandis, S. N., Barnes, I., Dentener, F. J., Facchini, M. C., Van Dingenen, R., Ervens, B., Nenes, A., Nielsen, C. J., Swietlicki, E., Putaud, J. P., Balkanski, Y., Fuzzi, S., Horth, J., Moortgat, G. K., Winterhalter, R., Myhre, C. E. L., Tsigaridis, K., Vignati, E., Stephanou, E. G., and Wilson, J.: Organic aerosol and global climate modelling: a review, Atmos. Chem. Phys., 5, 1053-1123, 2005, http://www.atmos-chem-phys.net/5/1053/2005/.

Kavouras, I. G., Mihalopoulos, N., and Stephanou, E. G.: Formation of atmospheric particles from organic acids produced by forests, Nature, 395, 683-686, 1998.

Koch, S., Winterhalter, R., Uherek, E., Kolloff, A., Neeb, P., and Moortgat, G. K.: Formation of new particles in the gas-phase ozonolysis of monoterpenes, Atmos. Environ., 34, 4031-4042, 2000.

Kroll, J. H. and Seinfeld, J. H.: Chemistry of secondary organic aerosol: Formation and evolution of low-volatility organics in the atmosphere, Atmos. Environ., 42, 3593-3624, 2008.

Larsen, B. R., Di Bella, D., Glasius, M., Winterhalter, R., Jensen, N. R., and Hjorth, J.: Gas-phase $\mathrm{OH}$ oxidation of monoterpenes: Gaseous and particulate products, J. Atmos. Chem., 38, 231-276, 2001.

Lee, A., Goldstein, A. H., Keywood, M. D., Gao, S., Varutbangkul, V., Bahreini, R., Ng, N. L., Flagan, R. C., and Seinfeld, J. H.: Gasphase products and secondary aerosol yields from the ozonolysis of ten different terpenes, J. Geophys. Res., 111, D07302, doi:10.1029/2005JD006437, 2006.

Ma, Y., Russell, A. T., and Marston, G.: Mechanisms for the formation of secondary organic aerosol components from the gasphase ozonolysis of $\alpha$-pinene, Phys. Chem. Chem. Phys., 10, 4294-4312, 2008.

Mackay, D., Bobra, A., Chan, D. W., and Shiu, W. Y.: Vaporpressure correlations for low-volatility environmental chemicals, Environ. Sci. Technol., 16, 645-649, 1982.

Martin, C. J.: Chemical models for, and the role of data and provenance in, an atmospheric chemistry community, School of Chemistry/School of Computing, University of Leeds, Ph.D. thesis, 2009.

McLafferty, F. W. and Turecek, F.: Interpretation of mass spectra, University Science Books, CA, 1993.

Müller, L., Reinnig, M.-C., Warnke, J., and Hoffmann, Th.: Unambiguous identification of esters as oligomers in secondary organic aerosol formed from cyclohexene and cyclohexene $/ \alpha$ pinene ozonolysis, Atmos. Chem. Phys., 8, 1423-1433, 2008, http://www.atmos-chem-phys.net/8/1423/2008/.

Muller, L., Reinnig, M. C., Hayen, H., and Hoffmann, T.: Characterization of oligomeric compounds in secondary organic aerosol using liquid chromatography coupled to electrospray ionization Fourier transform ion cyclotron resonance mass spectrometry, Rapid Commun. Mass Sp., 23, 971-979, 2009.

Myrdal, P. B. and Yalkowsky, S. H.: Estimating pure component vapor pressures of complex organic molecules, Ind. Eng. Chem. Res., 36, 2494-2499, 1997. 
Nannoolal, Y., Rarey, J., Ramjugernath, D., and Cordes, W.: Estimation of pure component properties Part 1, Estimation of the normal boiling point of non-electrolyte organic compounds via group contributions and group interactions, Fluid Phase Equilibr., 226, 45-63, 2004.

Nannoolal, Y., Rarey, J., and Ramjugernath, D.: Estimation of pure component properties, Part 3, Estimation of the vapor pressure of non-electrolyte organic compounds via group contributions and group interactions, Fluid Phase Equilibr., 269, 117-133, 2008.

Noziere, B. and Riemer, D. D.: The chemical processing of gas-phase carbonyl compounds by sulfuric acid aerosols-2,4pentanedione, Atmos. Environ., 37, 841-851, 2003.

Odum, J. R., Hoffmann, T., Bowman, F., Collins, D., Flagan, R. C., and Seinfeld, J. H.: Gas/particle partitioning and secondary aerosol yields, Environ. Sci. Technol., 30, 2580-2585, 1996.

Pankow, J. F.: An absorption model of gas/particle partitioning of organic compounds in the atmosphere, Atmos. Environ., 28, 185-188, 1994a.

Pankow, J. F.: An absorption model of the gas/aerosol partioning involved in the formation of secondary organic aerosol, Atmos. Environ., 28, 189-193, 1994b.

Peeters, J., Vereecken, L., and Fantechi, G.: The detailed mechanism of the $\mathrm{OH}$-initiated atmospheric oxidation of $\alpha$-pinene: a theoretical study, Phys. Chem. Chem. Phys., 3, 5489-5504, 2001.

Reid, R. C., Prausnitz, J. M., and Polling, B. E.: The properties of gases and liquids, 4th edition, McGraw-Hill, Inc., New York, 1986.

Reinhardt, A., Emmenegger, C., Gerrits, B., Panse, C., Dommen, J., Baltensperger, U., Zenobi, R., and Kalberer, M.: Ultrahigh mass resolution and accurate mass measurements as a tool to characterize oligomers in secondary organic, Anal. Chem., 79, 4074-4082, 2007.

Reinnig, M. C., Muller, L., Warnke, J., and Hoffmann, T.: Characterization of selected organic compound classes in secondary organic aerosol from biogenic VOCs by HPLC/MSn, Anal. Bioanal. Chem., 391, 171-182, 2008.

Rickard, A. R., Wyche, K. P., Metzger, A., Monks, P. S., Ellis, A. M., Dommen, J., Baltensperger, U., Jenkin, M. E., and Pilling, M. J.: Gas phase precursors to anthropogenic secondary organic aerosol: Using the Master Chemical Mechanism to probe detailed observations of 1,3,5-trimethylbenzene photooxidation, Atmos. Environ., in press, doi:10.1016/j.atmosenv.2009.09.043, 2009.

Sadezky, A., Chaimbault, P., Mellouki, A., Römpp, A., Winterhalter, R., Le Bras, G., and Moortgat, G. K.: Formation of secondary organic aerosol and oligomers from the ozonolysis of enol ethers, Atmos. Chem. Phys., 6, 5009-5024, 2006,

http://www.atmos-chem-phys.net/6/5009/2006/.

Saunders, S. M., Jenkin, M. E., Derwent, R. G., and Pilling, M. J.: Protocol for the development of the Master Chemical Mechanism, MCM v3 (Part A): tropospheric degradation of nonaromatic volatile organic compounds, Atmos. Chem. Phys., 3, 161-180, 2003, http://www.atmos-chem-phys.net/3/161/2003/.

Seinfeld, J. H. and Pankow, J. F.: Organic atmospheric particulate material, Annu. Rev. Phys. Chem., 54, 121-140, 2003.
Smith, D. and Spanel, P.: Selected ion flow tube mass spectrometry (SIFT-MS) for on-line trace gas analysis, Mass Spectrom. Rev., 24, 661-700, 2005.

Stein, S. E. and Brown, R. L.: Estimation of Normal Boiling Points from Group Contributions, J. Chem. Inf. Comp. Sci., 34, 581587, 1994.

Stroud, C. A., Makar, P. A., Michelangeli, D. V., Mozurkewich, M., Hastie, D. R., Barbu, A., and Humble, J.: Simulating organic aerosol formation during the photooxidation of toluene/ $\mathrm{NO}_{\mathrm{x}}$ mixtures: comparing the equilibrium and kinetic assumption, Environ. Sci. Technol., 38, 1471-1479, 2004.

Surratt, J. D., Murphy, S. M., Kroll, J. H., Ng, N. L., Hildebrandt, L., Sorooshian, A., Szmigielski, R., Vermeylen, R., Maenhaut, W., Claeys, M., Flagan, R. C., and Seinfeld, J. H.: Chemical composition of secondary organic aerosol formed from the photooxidation of isoprene, J. Phys. Chem. A, 110, 9665-9690, 2006.

Tobias, H. J., Kooiman, P. M., Docherty, K. S., and Ziemann, P. J.: Real-time chemical analysis of organic aerosols using a thermal desorption particle beam mass spectrometer, Environ. Sci. Technol., 33, 170-190, 2000.

Tobias, H. J. and Ziemann, P. J.: Thermal desorption mass spectrometric analysis of organic aerosol formed from reactions of 1-tetradecene and $\mathrm{O}_{3}$ in the presence of alcohols and carboxylic acids, Environ. Sci. Technol., 34, 2105-2115, 2000.

Tolocka, M. P., Jang, M., Ginter, J. M., Cox, F. J., Kamens, R. M., and Johnston, M. V.: Formation of oligomers in secondary organic aerosol, Environ. Sci. Technol., 38, 1428-1434, 2004.

Venkatachari, P. and Hopke, P. K.: Characterization of products formed in the reaction of ozone with alpha-pinene: case for organic peroxides, J. Environ. Monitor., 10, 966-974, 2008.

Vereecken, L. and Peeters, J.: Nontraditional (per)oxy ring-closure paths in the atmospheric oxidation of isoprene and monoterpenes, J. Phys. Chem. A, 108, 5197-5204, 2004.

Vereecken, L., Müller, J.-F., and Peeters, J.: Low-volatility polyoxygenates in the $\mathrm{OH}$-initiated atmospheric oxidation of $\alpha$ pinene: impact of non-traditional peroxyl radical chemistry, Phys. Chem. Chem. Phys., 9, 5241-5248, 2007.

Volkamer, R., Jimenez, J. L., San Martini, F., Dzepina, K., Zhang, Q., Salcedo, D., Molina, L. T., Worsnop, D. R., and Molina, M. J.: Secondary organic aerosol formation from anthropogenic air pollution: rapid and higher than expected, Geophys. Res. Lett., 33, L17811, doi:10.1029/2006GL026899, 2006.

Walser, M. L., Desyaterik, Y., Laskin, J., Laskin, A., and Nizkorodov, S. A.: High-resolution mass spectrometric analysis of secondary organic aerosol produced by ozonation of limonene, Phys. Chem. Chem. Phys., 10, 1009-1022, 2008.

Wyche, K. P., Blake, R. S., Willis, K. A., Monks, P. S., and Ellis, A. M.: Differentiation of isobaric compounds using chemical ionization reaction mass spectrometry, Rapid Commun. Mass Sp., 19, 3356-3362, 2005.

Wyche, K. P., Blake, R. S., Ellis, A. M., Monks, P. S., Brauers, T., Koppmann, R., and Apel, E. C.: Technical Note: Performance of Chemical Ionization Reaction Time-of-Flight Mass Spectrometry (CIR-TOF-MS) for the measurement of atmospherically significant oxygenated volatile organic compounds, Atmos. Chem. Phys., 7, 609-620, 2007, http://www.atmos-chem-phys.net/7/609/2007/. 
Wyche, K. P., Monks, P. S., Ellis, A. M., Cordell, R. L., Parker, A. E., Whyte, C., Metzger, A., Dommen, J., Duplissy, J., Prevot, A. S. H., Baltensperger, U., Rickard, A. R., and Wulfert, F.: Gas phase precursors to anthropogenic secondary organic aerosol: detailed observations of 1,3,5-trimethylbenzene photooxidation, Atmos. Chem. Phys., 9, 635-665, 2009, http://www.atmos-chem-phys.net/9/635/2009/.

Xia, A. G., Michelangeli, D. V., and Makar, P. A.: Box model studies of the secondary organic aerosol formation under different $\mathrm{HC} / \mathrm{NO}_{\mathrm{x}}$ conditions using the subset of the Master Chemical Mechanism for $\alpha$-pinene oxidation, J. Geophys. Res., 113, D10301, doi:10.1029/2007JD008726, 2008.

Yu, J. Z., Flagan, R. C., and Seinfeld, J. H.: Identification of products containing $-\mathrm{COOH},-\mathrm{OH}$, and $-\mathrm{C}=\mathrm{O}$ in atmospheric oxidation of hydrocarbons, Environ. Sci. Technol., 32, 2357-2370, 1998.

Yu, J., Cocker, D. R., Griffin, R. J., Flagan, R. C., and Seinfeld, J. H.: Gaz-phase ozone oxydation of monoterpenes: gazeous and particulate products, J. Atmos. Chem., 34, 207-258, 1999.
Yu, Y., Ezell, M. J., Zelenyuk, A., Imre, D., Alexander, L., Ortega, J., D’ Anna, B., Harmon, C. W., Johnson, S. N., and FinlaysonPitts, B. J.: Photooxidation of alpha-pinene at high relative humidity in the presence of increasing concentrations of $\mathrm{NO}_{\mathrm{x}}$, Atmos. Environ., 42, 5044-5060, 2008.

Zahardis, J. and Petrucci, G. A.: The oleic acid-ozone heterogeneous reaction system: products, kinetics, secondary chemistry, and atmospheric implications of a model system - a review, Atmos. Chem. Phys., 7, 1237-1274, 2007, http://www.atmos-chem-phys.net/7/1237/2007/.

Zelenyuk, A., Yang, J., Song, C., Zaveri, R. A., and Imre, D.: A new real-time method for determining particles' sphericity and density: application to secondary organic aerosol formed by ozonolysis of $\alpha$-pinene, Environ. Sci. Technol., 42, 8033-8038, 2008.

Ziemann, P. J.: Evidence for low-volatility diacyl peroxides as a nucleating agent and major component of aerosol formed from reactions of $\mathrm{O}^{-3}$ with cyclohexene and homologous compounds, J. Phys. Chem. A, 106, 4390-4402, 2002. 